\title{
Amino Acids Are an Ineffective Fertilizer for Dunaliella spp. Growth
}

\author{
Colin A. Murphree ${ }^{1}$, Jacob T. Dums ${ }^{1}$, Siddharth K. Jain ${ }^{1+}$, Chengsong Zhao ${ }^{2}$, \\ Danielle Y. Young ${ }^{1}$, Nicole Khoshnoodi ${ }^{3 t}$, Andrey Tikunov ${ }^{4}$, Jeffrey Macdonald ${ }^{4}$, \\ Guillaume Pilot ${ }^{2}$ and Heike Sederoff ${ }^{1 *}$
}

\begin{abstract}
${ }^{1}$ Department of Plant and Microbial Biology, North Carolina State University, Raleigh, NC, United States, ${ }^{2}$ Department of Plant Pathology, Physiology, and Weed Science, Virginia Polytechnic Institute and State University, Blacksburg, VA, United States, ${ }^{3}$ Research Triangle High School, Durham County, NC, United States, ${ }^{4}$ Department of Biomedical Engineering, University of North Carolina School of Medicine, Chapel Hill, NC, United States
\end{abstract}

Autotrophic microalgae are a promising bioproducts platform. However, the fundamental requirements these organisms have for nitrogen fertilizer severely limit the impact and scale of their cultivation. As an alternative to inorganic fertilizers, we investigated the possibility of using amino acids from deconstructed biomass as a nitrogen source in the genus Dunaliella. We found that only four amino acids (glutamine, histidine, cysteine, and tryptophan) rescue Dunaliella spp. growth in nitrogen depleted media, and that supplementation of these amino acids altered the metabolic profile of Dunaliella cells. Our investigations revealed that histidine is transported across the cell membrane, and that glutamine and cysteine are not transported. Rather, glutamine, cysteine, and tryptophan are degraded in solution by a set of oxidative chemical reactions, releasing ammonium that in turn supports growth. Utilization of biomass-derived amino acids is therefore not a suitable option unless additional amino acid nitrogen uptake is enabled through genetic modifications of these algae.

Keywords: Dunaliella, nitrogen recycling, lipids, biofuel, amino acids, sustainability

\section{INTRODUCTION}

Autotroph algae have gained attention in recent years because they are potentially a valuable bioproduct feedstock. These organisms could produce large quantities of high value proteins, chemicals, or combustible hydrocarbons on a relatively small acreage, and may operate with less environmental impact than conventional agriculture or fossil fuels (Wijffels and Barbosa, 2010; Georgianna and Mayfield, 2012; Rasala and Mayfield, 2015). The theoretical energy yield for biofuel production from algae per unit area is estimated to be between 30- and 300-fold higher than any available crop system (Sheehan et al., 1998; Packer, 2009), and these organisms may eventually be productive enough to satisfy a large proportion of fuel consumption using non-arable land (US Department of Energy, 2010; Moody et al., 2014). In addition, some fuel producing microalgae thrive in marine environments, and therefore their production could be supported entirely using non-potable water sources such as ocean water. However, the viability of growing algae at scale for any purpose is limited by the requirements these organisms have for nitrogen and phosphorous fertilizers. The demand for these fertilizers is such that if only $10 \%$ of transportation fuels needed in the US for 2010 were replaced by algal biodiesel, it would require an amount of nitrogen fertilizer equivalent to $175 \%$ of total annual US production (Grobbelaar, 2004; Chisti, 2013). This is considerable, as the production of synthetic $\mathrm{N}$-fertilizer via the Haber-Bosch process is reliant on 
energy derived from fossil fuels. Furthermore, the use of fertilizer in agriculture effectively creates nitrogen pollution in the form of nitrous oxides, a greenhouse gas, which is thought to offset gains in the global warming potential of biofuels (Crutzen et al., 2008; Erisman et al., 2008; Galloway et al., 2008; Bobbink et al., 2010). There is therefore a need to address the impacts of nitrogen fertilizer use within the bioeconomy.

One solution is to reduce both fertilizer inputs and nitrogen waste by creating an effective nitrogen recycling scheme. Many groups have proposed using thermochemical conversion and anaerobic digestion of biomass as potential sources of recycled nitrogen (Minowa et al., 1995; Chisti, 2008; Sialve et al., 2009; Jena et al., 2011; Biller et al., 2012; Huo et al., 2012; Garcia Alba et al., 2013; López Barreiro et al., 2013a). These degradative approaches have the benefit that phosphorous and nitrogen can be resupplied in an inorganic form, and theoretically enable the possibility of growing multiple culture generations from a single fertilizer input. However, the feasibility of these approaches remains questionable because of the high nitrogen content of biomass and the energetic costs of concentrating algae for these applications (Mata-Alvarez et al., 2000; Chen et al., 2008; Lam and Lee, 2012; López Barreiro et al., 2013b; Ward et al., 2014). Both approaches result in the production of ammonium as the most abundant form of recycled nitrogen (Tsukahara et al., 2001; Sialve et al., 2009). Consequently, the $\mathrm{pH}$ of cultivation medium and ammonium concentration must be tightly controlled in any resulting algal growth system to prevent toxicity resulting from electrochemical gradient decoupling (Azov and Goldman, 1982). Furthermore, these approaches may be incompatible with the use of marine and saline algae feedstocks, as the salt content of this biomass is corrosive or inhibitory to thermochemical and biological degradation schemes (McCarty, 1964; Parkin and Owen, 1986; Chen et al., 2008; Vergara-Fernández et al., 2008; Ward et al., 2014).

An alternative scheme would be to recycle the nitrogenrich biomass of algae in an organic form. The proposed strategy is to use an in vitro process to degrade algal biomass (proteins and nucleic acids) after extraction of non-polar lipid products into nitrogen-containing organic monomers (amino acids, nucleotides), and then to replace inorganic nitrogen fertilizer in algae production with those monomers (Figure 1). Specifically, protease and nuclease enzymes would be applied to algal biomass in a bioreactor to generate amino and nucleic acids in the same manner as amylase is added to starch to generate the sugars used in the industrial production of ethanol. The enzymatically treated biomass slurry would then be introduced into the algal cultivation medium in lieu of inorganic nitrogen and phosphorous fertilizer. Importantly, this strategy relies on the capacity of a species of alga to use organic nitrogen and phosphorous containing compounds as a fertilizer source. It is also imperative that utilization of these organic nitrogen and phosphorous monomers maintains the productivity of a desired product, such as triacylglycerols (TAGs).

There is reason to suspect that biofuel-producing autotrophic algae would be able to use amino acids, as marine and freshwater autotrophic algae have demonstrated the ability to grow on amino acid-supplemented media (Cain, 1965; Wheeler et al., 1974; Palenik and Morel, 1990; Zhang et al., 2015). Autotrophic algae have at least two mechanisms by which the nitrogen from amino acids could be acquired. Like plants (Fischer et al., 1998; Tegeder, 2012; Tegeder and Ward, 2014), algae possess channels or transporters that could facilitate movement of amino acids into the cell (Kirk and Kirk, 1978a,b; Sauer, 1984; Cho and Le Gal, 1985). In addition, it has been shown that algae possess extracellular enzymes that deaminate amino moieties, releasing ammonium that can be transported across the cell membrane and subsequently assimilated via the GS-GOGAT cycle (MunozBlanco et al., 1990; Palenik and Morel, 1990, 1991; Piedras et al., 1992; Vallon et al., 1993) into biomass. Some amino acids are unstable when present in aqueous solution and when exposed to light, forming $\mathrm{NH}_{4}{ }^{+}$, urea, and other amino acids over time (Asquith and Hirst, 1969; Tomita et al., 1969; Abraham and Podell, 1981; Gracanin et al., 2009; Pattison et al., 2012).

The viability and effects of feeding amino acids as a nitrogen source was investigated using the genus Dunaliella. Dunaliella spp. are motile, unicellular, autotrophic, halophitic algae that are often isolated from extreme saline environments (Borowitzka and Siva, 2007). Triacylglycerols can be extracted from these algae by osmotic cell lysis or solvent extraction (Wang et al., 2013). As a biofuel production platform, Dunaliella spp. are advantageous as they would not compete for arable land or freshwater for growth. Dunaliella spp. have been cultivated using a number of different nitrogen sources, including $\mathrm{NH}_{4}{ }^{+}, \mathrm{NO}_{3}{ }^{-}, \mathrm{NO}_{2}{ }^{-}, \mathrm{NO}$, urea, histidine, glutamine, hypoxanthine, and allantoate (Goldman and Peavey, 1979; Latorella et al., 1981; Fabregas et al., 1989; Giordano et al., 1994; Giordano, 1997; Hellio and Le Gal, 1998; Nagase et al., 2001). Uptake of histidine in Dunaliella tertiolecta was demonstrated previously (Hellio and Le Gal 1998, 1999), but the mechanism of uptake, the identity of the transporter responsible, and any effects on metabolism remain unknown.

We determined the ability of four Dunaliella species to utilize 20 proteinogenic amino acids supplied individually as a sole nitrogen source. Only four amino acids [glutamine (Gln, Q), cysteine (Cys, C), histidine (His, H), and tryptophan (Trp, W)] recovered growth of Dunaliella from nitrogen starvation. Supplementation of these amino acids resulted in a set of unique metabolite profile changes. The mechanism by which Dunaliella spp. obtain nitrogen from these amino acids was also investigated. We found evidence for the uptake of histidine in one strain of $D$. viridis; however, it remains unknown how this amino acid is assimilated. In contrast, glutamine, cysteine, and tryptophan appear to oxidize in the presence of light, supplying $\mathrm{NH}_{4}{ }^{+}$that is likely transported across the cell membrane by Dunaliella spp. and assimilated by the GS-GOGAT pathway.

\section{MATERIALS AND METHODS}

\section{Strains and Growth Conditions}

The Dunaliella strains used in this study (D. salina CCAP 19/18, D. viridis dumsii, D. tertiolecta CCMP 364, D. primolecta UTEX LB1000) were obtained from the Culture Collection of Algae 


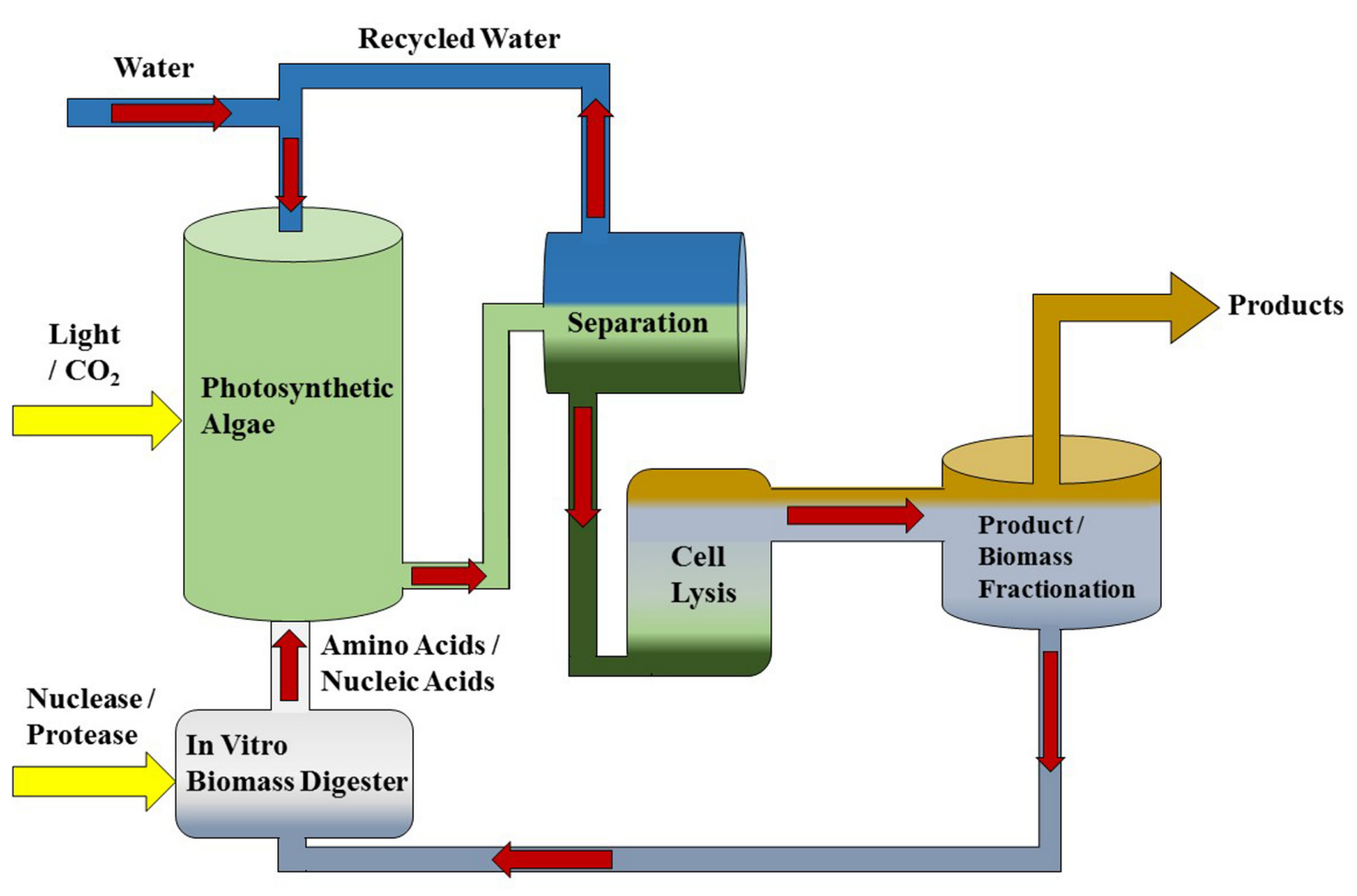

FIGURE 1 | Diagram of a microalgae production system featuring in vitro biomass recycling. This production system is intended to work with any photosynthetic microalgae platform such as Dunaliella that produces extractable lipids or high value co-products. In vitro nutrient recycling is performed in a separate bioreactor to generate $\mathrm{N}$ and $\mathrm{P}$ organic monomers from algal biomass that are intended as a substitute for fertilizer additions.

and Protozoa $\left(\mathrm{CCAP}^{1}\right)$, National Center for Marine Algae and Microbiota $\left(\mathrm{NCMA}^{2}\right)$, or $\mathrm{UTEX}^{3}$.

Strains were grown in $125 \mathrm{ml}$ Erlenmeyer flasks containing modified Ben-Amotz media (mBA, pH 7.5) (Ben-Amotz et al., 1989; Srirangan et al., 2015) and maintained in exponential phase prior to inoculation of growth experiments. All cultures (except those used in uptake assays, see below) were grown at $21^{\circ} \mathrm{C}$ under continuous cool white fluorescent light with an intensity of $150 \mu \mathrm{mol}$ photons $\mathrm{m}^{-2} \mathrm{~s}^{-1}$ at the culture surface.

\section{Nitrogen Source Growth Experiments}

Nitrogen source growth experiments were carried out in batch culture using filter-sterilized mBA lacking nitrogen (mBA -N) medium in $4 \mathrm{ml}$ volumes within 12 -well polystyrene tissue culture plates. The cell density of Dunaliella cultures was quantified using a TC10 Automated Cell Counter (Bio-Rad). For each biological replicate, $8 \times 10^{7}$ cells were harvested by centrifugation at $3,441 \times g$ for $2 \mathrm{~min}$. The supernatant was discarded and cultures were washed in $\mathrm{mBA}-\mathrm{N}$. These cell suspensions were again centrifuged, the supernatant was discarded, and cells were re-suspended in $1 \mathrm{ml}$ of $\mathrm{mBA}-\mathrm{N}$. An inoculum of $4.0 \times 10^{6}$ cells in a volume of $50 \mu \mathrm{l}$ was used to seed each well containing media. For cultures of $D$. salina, only $2 \times 10^{6}$ cells were used.

${ }^{1}$ http://www.ccap.ac.uk/

${ }^{2} \mathrm{https} / /$ ncma.bigelow.org/

${ }^{3}$ https://utex.org/
Cells were mixed and the density of each well was recorded. Plates were then wrapped with parafilm and grown for $144 \mathrm{~h}$ under the conditions described above. At 0 and $144 \mathrm{~h}$ post-inoculation, cultures were mixed and the cell densities and diameter were determined. There were four biological replicates used for each Dunaliella strain.

\section{Urea Transporter and Enzyme Search}

High affinity urea transport in plants is carried out by homologs of the yeast DUR3 urea transporter (Kojima et al., 2006). To find Dunaliella DUR3 homologs, yeast DUR3 (yeastgenome.org: YHL016C) and Arabidopsis thaliana AtDUR3 (TAIR: AT5G45380) protein sequences were used as BLAST queries against the D. salina CCAP 19/18 genome $^{4}$ and against the assembled transcriptomes of $D$. viridis strain dumsii (Srirangan et al., 2015), D. tertiolecta CCMP 364, and D. primolecta UTEX 1000 (Matasci et al., 2014). Blast hits that also contained the conserved domain PF00474 were considered to be DUR3 homologs (Finn et al., 2016).

The metabolism of urea to ammonia in organisms can be accomplished via two different routes. The first consists of a nickel dependent urease producing ammonia and carbon dioxide. The second method uses urea carboxylase and allophanate hydrolase to convert urea to ammonium and bicarbonate through an allophanate intermediate (Fan et al.,

\footnotetext{
${ }^{4}$ http://phytozome.jgi.doe.gov/
} 
2012). The urease protein sequence from A. thaliana (TAIR: AT1G67550) and the urea carboxylase (Phytozome_v11: Cre08.g360050.t1.1) and allophanate hydrolase (Phytozome_v11: Cre08.g360100.t1.2) protein sequences from Chlamydomonas reinhardtii (Merchant et al., 2007) were used as BLAST queries against the D. salina CCAP 19/18 genome $^{5}$ and against the assembled transcriptomes of $D$. viridis strain dumsii (Srirangan et al., 2015), D. tertiolecta CCMP 364, and D. primolecta UTEX 1000 (Matasci et al., 2014).

\section{Metabolite Quantification Chlorophyll}

Culture samples of one $\mathrm{ml}$ were harvested by centrifugation for $10 \mathrm{~min}$ at $16,000 \times g$. The supernatant was removed and $625 \mu \mathrm{l}$ of $100 \% \mathrm{EtOH}$ was added to the remaining pellet. Samples were resuspended by vortexing and incubated at room temperature for $1 \mathrm{~h}$. Samples were mixed every $15 \mathrm{~min}$ and then centrifuged for $10 \mathrm{~min}$ at $16,000 \times \mathrm{g}$. The chlorophyll content was measured as absorption at $652 \mathrm{~nm}$ with $100 \% \mathrm{EtOH}$ as a background control. The total chlorophyll amount $\left(\mu \mathrm{g} \mathrm{ml}^{-1}\right)$ was calculated as $\mathrm{A}_{652} / 36$ (36 = extinction coefficient) (Arnon, 1949).

\section{Neutral Lipid}

Generation of coconut oil standards used in calibration curve Absolute neutral lipid concentration was determined using coconut oil in mBA containing $0.01 \%$ Tween as a standard. Briefly, $10 \mathrm{mg}$ of coconut oil was melted and added to $5 \mathrm{ml}$ of mBA containing $0.2 \%$ Tween $\left(2000 \mu \mathrm{g} \mathrm{ml}^{-1}\right)$ and sonicated for 20 min using a Microson Ultrasonic Cell Disruptor set to 5 watts. The sonicated coconut oil solution was diluted in mBA containing $0.05 \%$ tween $\left(500 \mu \mathrm{g} \mathrm{ml}^{-1}\right.$ ) and sonicated for a further $20 \mathrm{~min}$ at 5 watts. Coconut oil standards of 5-100 $\mu \mathrm{g}$ $\mathrm{ml}^{-1}$ were prepared from freshly made $500 \mu \mathrm{g} \mathrm{ml}^{-1}$ coconut oil stocks by serial dilution using mBA containing $0.01 \%$ Tween.

\section{Neutral lipid quantification}

Neutral lipid accumulation was quantified using Nile Red (9diethylamino-5H-benzo $(\alpha)$ phenoxazine-5-one; Sigma-Aldrich, United States) following the method of Elsey with modifications (Elsey et al., 2007). Freshly prepared $0.78 \mathrm{mM}$ Nile red in acetone was added to a final concentration of $0.26 \mu \mathrm{M}$ in each cell culture or coconut oil standard and mixed. Each resulting suspension was split into three $200 \mu \mathrm{l}$ replicates in a polystyrene microplate and read with a microplate reader using fluorescence excitation of $485 \mathrm{~nm}$ and emission of $590 \mathrm{~nm}$. Samples were incubated in darkness for approximately $15 \mathrm{~min}$ prior to reading. Sterile $\mathrm{mBA}$, as well as $\mathrm{mBA}$ containing $0.01 \%$ tween were used as background controls for cell cultures and coconut oil standards, respectively.

\section{Carbohydrate Quantification}

Total carbohydrate concentration was determined by the Dubois method amended for use in a 96 well plate (Dubois et al., 1956). $0.5 \mathrm{ml}$ of each cell culture was centrifuged for $10 \mathrm{~min}$ at $16,000 \times g$. The supernatant was removed and the cells were

\footnotetext{
${ }^{5}$ http://phytozome.jgi.doe.gov/
}

lysed in $0.5 \mathrm{ml}$ of distilled $\mathrm{H}_{2} \mathrm{O}$. Sucrose standards of 5 to $500 \mu \mathrm{g} \mathrm{ml}^{-1}$ were prepared in distilled $\mathrm{H}_{2} \mathrm{O}$. Each standard or sample was split into triplicate $40 \mu \mathrm{l}$ aliquots in clear polystyrene 96 well plates. Crystalline phenol in $\mathrm{H}_{2} \mathrm{O}$ was freshly made to a concentration of $5 \% \mathrm{w} / \mathrm{v}$ and $40 \mu \mathrm{l}$ of was added to each sample and mixed. After $15 \mathrm{~min}, 200 \mu \mathrm{l}$ of $95-98 \%$ sulphuric acid was added, and samples were immediately mixed 20 times by pipetting. Plates were cooled to room temperature data was quantified by measuring absorption at $490 \mathrm{~nm}$ using a microplate reader.

\section{Soluble Protein}

Soluble protein extraction and quantification was performed as previously described with modification (Srirangan et al., 2015). No $\beta$-mercaptoethanol was used for re-extraction.

\section{Quantification of Free $\mathrm{NH}_{4}{ }^{+}$in Growth Medium}

Free $\mathrm{NH}_{4}{ }^{+}$in growth medium was quantified using the phenate method amended for use with mBA medium in a 96 well plate (Eppley et al., 1969). $\mathrm{NH}_{4}{ }^{+}$standards of 5 to 2,000 $\mu \mathrm{g} \mathrm{ml}^{-1}$ were made using $\mathrm{NH}_{4} \mathrm{Cl}$ in mBA -N. Each sample or $\mathrm{NH}_{4}{ }^{+}$standard was added in triplicate $50 \mu \mathrm{l}$ aliquots to 96 well microplate. To each aliquot, $40 \mu \mathrm{l}$ of $20 \%(\mathrm{w} / \mathrm{v})$ crystalline phenol in $\mathrm{EtOH}$ and $40 \mu \mathrm{l} 0.5 \%(\mathrm{w} / \mathrm{v})$ sodium nitroprusside in distilled $\mathrm{H}_{2} 0$ were added and mixed. A $10 \mathrm{ml}$ solution of $20 \%$ (w/v) sodium citrate and $2 \% \mathrm{NaOH}$ in distilled $\mathrm{H}_{2} \mathrm{O}$ was combined with $3.5 \mathrm{ml}$ of commercial bleach (7.25\% sodium hypochlorite) and $70 \mu \mathrm{l}$ of the resulting solution was added to each well and immediately mixed 10 times. Plates were developed for $1 \mathrm{~h}$ in darkness. Free $\mathrm{NH}_{4}{ }^{+}$ was quantified by measuring absorption at $630 \mathrm{~nm}$.

\section{Uptake Assays}

Amino acid uptake assays for Dunaliella spp. were amended from a yeast protocol (Su et al., 2004). Briefly, $50 \mathrm{ml}$ Dunaliella cultures in mBA were maintained in a Conviron growth chamber (model number ATC60) under long-day condition (16 h light $/ 8 \mathrm{~h}$ dark, $22^{\circ} \mathrm{C} / 18^{\circ} \mathrm{C}$, respectively) and $135 \mu$ mol photons $\mathrm{m}^{-2} \mathrm{~s}^{-1}$ in exponential phase prior to inoculation of growth medium containing different nitrogen sources. From each growth medium, either $5 \times 10^{7}$ (Figure 5A) or $2 \times 10^{8}$ (Figure 5B) cells were harvested by centrifugation and suspended in $1 \mathrm{ml}$ of mBA -N. Each cell suspension was dispensed into $100 \mu \mathrm{l}$ aliquots. Aliquots were maintained on ice until $10 \mu \mathrm{l}$ of $1 \mathrm{M}$ glucose was added to each suspension, after which cells were mixed and incubated for 5 min under cool white fluorescent light at $25^{\circ} \mathrm{C}\left(40 \mu \mathrm{mol}\right.$ photons $\left.\mathrm{m}^{-2} \mathrm{~s}^{-1}\right)$. Uptake solutions were prepared by mixing non-labeled amino acid (final concentration of $1 \mathrm{mM}$ ) with two microliters of the following labeled amino acids at $\mathrm{mCi} \mathrm{ml} \mathrm{m}^{-1}$ : L-cystine $\left[3,3^{\prime}-{ }^{14} \mathrm{C}\right]$, L-histidine $\left[2,5-{ }^{3} \mathrm{H}\right]$, and L-glutamine $\left[3,4-{ }^{3} \mathrm{H}(\mathrm{N})\right]$. Uptake solution was mixed with incubated cell aliquots, yielding a final specific activity of $\sim 91$ $\mathrm{nCi} \mu \mathrm{l}^{-1}$. A portion of each sample $(50 \mu \mathrm{l})$ was taken at several time points and added to $5 \mathrm{ml}$ of $1 \mathrm{M} \mathrm{NaCl}$ on a DHI Filtration Manifold (CAT\# EQU-FM-10X20-SET) fitted with $24 \mathrm{~mm}$ glass filters (Whatman CAT\# 1822-024). The solution was removed by application of vacuum, and the washing was repeated two 
more times with $5 \mathrm{ml} 1 \mathrm{M} \mathrm{NaCl}$. The filters containing the cells were loaded into scintillation vials, $500 \mu \mathrm{l}$ of commercial bleach ( $5 \%$ sodium hypochlorite) was added to each scintillation vial. Radioactivity in each vial was measured using a BeckmanCoulter scintillation counter (LS6500 Multi-Purpose Scintillation Counter).

\section{NMR}

\section{Growth and Collection}

Cultures used for NMR detection of metabolites were scaled into $3 \mathrm{~L}$ glass Erlenmeyer flasks containing $1 \mathrm{~L}$ of growth medium. After an initial period of scale up, cells used for inoculation were mixed once daily and maintained in exponential phase. To perform each growth experiment to be analyzed by NMR, $4.0 \times 10^{9}$ cells were collected by centrifugation at $10,000 \times g$ for $15 \mathrm{~min}$. Supernatant was removed and cells were washed in mBA -N. Cells were then resuspended in $1 \mathrm{~L}$ of freshly made growth media supplemented with $5 \mathrm{mM}$ Gln. Cell pellets and spent media was either immediately collected for extraction $(T=0)$ or grown in $3 \mathrm{~L}$ flasks for 24 or $48 \mathrm{~h}$ before collection. Cell pellets were collected by centrifugation at $10,000 \times g$ for $15 \mathrm{~min}$. The resulting spent media supernatant was immediately frozen at $-80^{\circ} \mathrm{C}$. The rest of the supernatant was discarded, and the remaining cell pellet was washed twice with $1 \mathrm{M} \mathrm{NaCl}$. Wet cell pellets were immediately frozen at $-80^{\circ} \mathrm{C}$.

\section{Metabolite Extraction}

Metabolites were extracted from cell pellets with acetonitrile (Neumuller et al., 2013). Briefly, algal pellets were extracted with a $54 \%$ solution of acetonitrile in distilled $\mathrm{H}_{2} \mathrm{O}$. Each extraction underwent 3 freeze-thaw cycles using liquid nitrogen and $55^{\circ} \mathrm{C}$ water bath. Extractions were then centrifuged at $4,000 \times g$ for $5 \mathrm{~min}$. The resulting supernatant was collected in a $50 \mathrm{ml}$ conical vial, and the remaining pellet was re-extracted with $4 \mathrm{ml}$ of $60 \%$ acetonitrile. The re-extraction was centrifuged at $4,000 \times g$ for $5 \mathrm{~min}$ and the resulting supernatant was combined with the prior supernatant. This combined supernatant was then frozen at $-80^{\circ} \mathrm{C}$.

\section{${ }^{1} \mathrm{H}$ NMR Spectroscopy}

The acetonitrile:water (3:2) extracted algae was dried on a speedvac (Thermo-Fisher), and stored at $-80^{\circ} \mathrm{C}$ until NMR analysis. The extracted powder was re-suspended in $600 \mu \mathrm{l}$ of $\mathrm{D}_{2} \mathrm{O}$ containing $0.1 \mathrm{mM}$ trimethylsilyl-2,2,3,3-tetradeuteropropioninc acid (TSP) and $1 \mathrm{mM}$ formate and pipetted into a $5 \mathrm{~mm}$ NMR tube for subsequent high resolution NMR analysis. 1D one-pulse ${ }^{1} \mathrm{H}-\mathrm{NMR}$ spectra with water presaturation were acquired with $4 \mathrm{~s}$ recycle time using a $14.1 \mathrm{~T}$ Varian INOVA $\left(600 \mathrm{MHz}{ }^{1} \mathrm{H}\right.$ frequency, Varian Instruments, Palo Alto, CA, United States) equipped with a $5 \mathrm{~mm}$ indirect detection probe.

\section{NMR Spectral Analysis and Metabolite Identification}

All NMR spectra were processed using ACD/1D NMR Manager software (version 12.0; Advanced Chemistry Development, Inc., Toronto, ON, Canada). Imported FIDs were zero-filled to 64,000 points, and an exponential line broadening of $0.3 \mathrm{~Hz}$ was applied prior to Fourier transformation. Spectra were phase and baseline corrected and referenced to the TSP peak at $0.00 \mathrm{ppm}$.

Metabolite identification was performed by comparing NMR spectral identifiers (chemical shifts, peak area ratios, peak multiplicity, coupling constants) were compared to metabolomic NMR databases [Human Metabolome Database ${ }^{6}$; University of Wisconsin $\left.{ }^{7}\right]$ and to known breakdown products of glutamate, such as pyroglutamate (Abraham and Podell, 1981). Metabolite quantification was determined using Chenomx software (version 5.1; Chenomx Inc., Edmonton, $\mathrm{AB}$, Canada) as previously described (Dewar et al., 2010).

\section{UPLC-MS Determination of Amino Acid Content}

The amino acid composition of $D$. viridis cells was determined using $8 \mathrm{ml}$ of culture grown for $144 \mathrm{~h}$. Samples were centrifuged for $10 \mathrm{~min}$ at $16,000 \times g$. Supernatant was removed and cells were lysed in $400 \mu \mathrm{l}$ of distilled water. Cell lysates were stored at $-20^{\circ} \mathrm{C}$ until derivatization. For total amino acid content analysis, $50 \mu \mathrm{l}$ of frozen cell lysates were thawed and hydrolyzed using $1 \mathrm{ml}$ vacuum hydrolysis tubes (Life Technologies) containing $400 \mu \mathrm{l}$ of $6 \mathrm{~N} \mathrm{HCl}$ with $0.02 \% \beta$-mercaptoethanol. Hydrolysis was carried out under vacuum and $105^{\circ} \mathrm{C}$ for $20 \mathrm{~h}$ and terminated using $400 \mu \mathrm{l}$ of $6 \mathrm{~N} \mathrm{NaOH}$.

Cell lysates and hydrolyzed cell lysates were separately derivatized with AccQ - Tag (Waters). Derivatized samples were run on a Waters UPLC system in reverse phase mode. Standard curves for each amino acid and ammonium were generated using amino acid standards from Sigma Aldrich (Catalog no.: AA-S-18) for a working range of 0 to $50 \mathrm{mM}$.

\section{Experimental Replication and Statistical Treatment}

For all data presented, at least three biological replicates were used. Statistical analysis was performed in Microsoft Excel. A Student's $t$-test was used for all comparisons between two means. Tukey's HSD was used to establish significant groupings when performing multiple comparisons.

\section{RESULTS}

\section{Dunaliella spp. Are Susceptible to Ammonium Toxicity and Vary in the Ability to Use Urea}

A screen was conducted to determine whether various organic and inorganic nitrogen substrates could support growth of D. viridis (Figure 2). Two surprising results of this nutrient screen were that (i) urea did not support growth of D. viridis and that (ii) $\mathrm{NH}_{4}{ }^{+}$in excess of $1 \mathrm{mM}$ was generally inhibitory or toxic to all Dunaliella species tested (Figure 3 and Table 1). Other Dunaliella species were able to grow to high density when supplemented

\footnotetext{
${ }^{6}$ http://www.hmdb.ca

${ }^{7}$ http://www.bmrb.wisc.edu/metabolomics/
} 


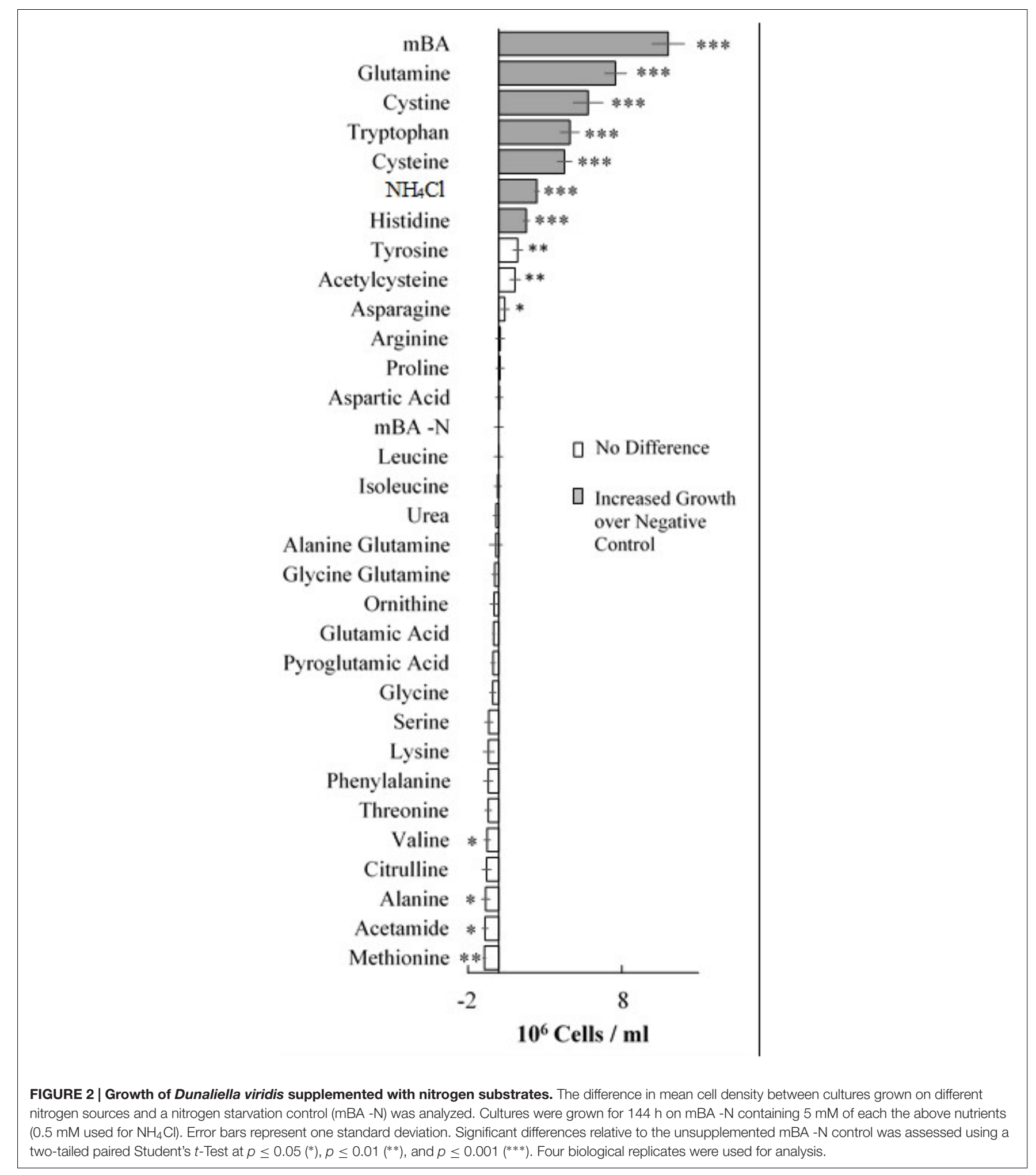

with urea, and also possessed gene sequence encoding likely transporters and enzymes necessary for urea utilization (Table 1). In contrast, $D$. viridis lacked any available sequence that might code for a urea transporter, and also does not appear to possess a sufficient set of enzymes needed for urea conversion (Table $\mathbf{1}$ ). $\mathrm{NH}_{4}{ }^{+}$above $2 \mathrm{mM}$ was inhibitory regardless of the species tested, a situation previously observed only in $D$. tertiolecta (Figure 3; Chen et al., 2011). Ribonucleoside and nucleobase monomers 


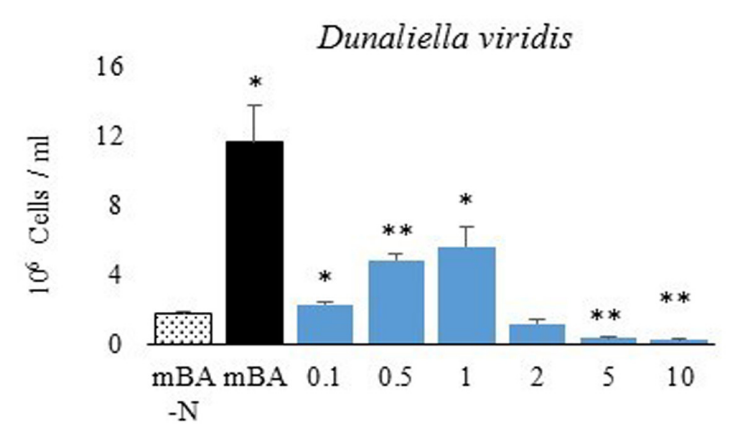

Dunaliella tertiolecta

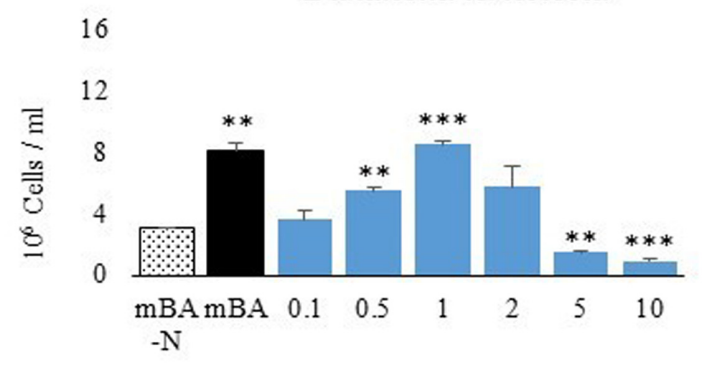

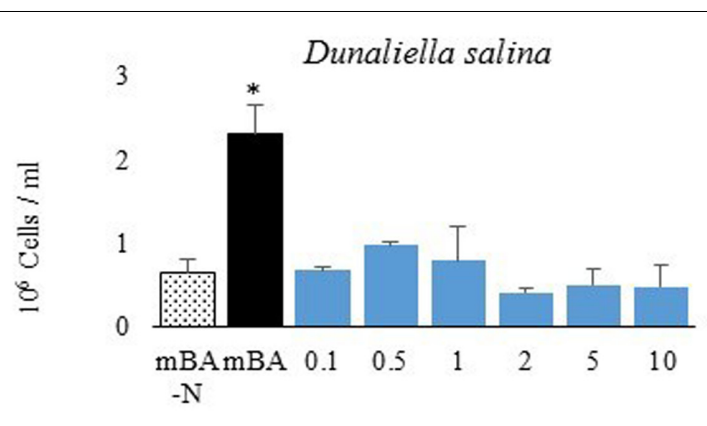

Dunaliella primolecta

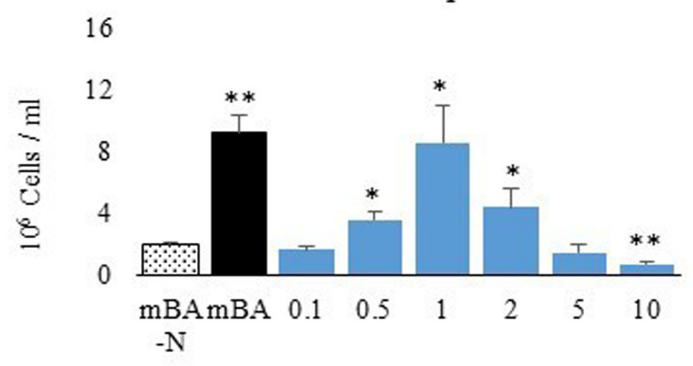

FIGURE 3 | Growth of Dunaliella spp. using $\mathrm{NH}_{4} \mathbf{C l}$ as the sole nitrogen source. Total cell density of cultures grown for $144 \mathrm{~h}$ on mBA-N containing $\mathrm{NH}_{4} \mathrm{Cl}$ at varied concentrations (in $\mathrm{mM}$ ). Average cell density was measured from four biological replicates. Error bars represent one standard deviation. Significant growth relative to the un-supplemented mBA $-\mathrm{N}$ control was assessed using a two-tailed paired Student's $t$-Test at $p \leq 0.05(*)$, $p \leq 0.01(* *)$, and $p \leq 0.001(* * *)$. Four biological replicates were used for analysis.

TABLE 1 | Variation in the ability of Dunaliella spp. to use urea as a nitrogen source.

\begin{tabular}{|c|c|c|c|c|c|c|c|}
\hline \multirow[t]{2}{*}{ Organism } & \multirow[t]{2}{*}{ Growth } & \multicolumn{4}{|c|}{ Number of Homologs Identified } & \multirow[t]{2}{*}{ Accessions } & \multirow[t]{2}{*}{ Reference } \\
\hline & & Urea Transporter & Urease & Urea Carboxylase & Allophanate Hydrolase & & \\
\hline D. viridis & & 0 & 0 & 1 & 0 & Locus_7748 & (Srirangan et al. (2015)) \\
\hline D. salina & $* *$ & 3 & 0 & 1 & 1 & $\begin{array}{l}\text { Dusal.0292s00003, } \\
\text { Dusal.0572s00011, } \\
\text { Dusal.1401s00001, } \\
\text { Dusal.0292s00001, } \\
\text { Dusal.0292s00002 }\end{array}$ & $*$ \\
\hline D. tertiolecta & $* * *$ & 1 & 0 & 1 & 1 & $\begin{array}{l}\text { ZDIZ-2004114, } \\
\text { ZDIZ-2004115, } \\
\text { ZDIZ-2051319 }\end{array}$ & (Matasci et al. (2014)) \\
\hline D. primolecta & $* * *$ & 1 & 0 & 1 & 1 & $\begin{array}{l}\text { WDWX-2002751, } \\
\text { WDWX-2002752, } \\
\text { WDWX-2045758 }\end{array}$ & (Matasci et al. (2014)) \\
\hline
\end{tabular}

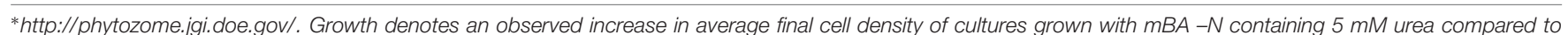

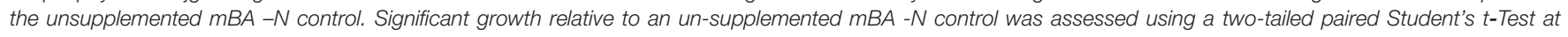

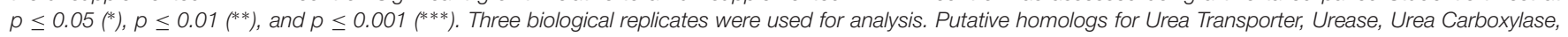
and Allophanate Hydrolase were identified using BLAST (see Materials and Methods).

were also evaluated as a nitrogen source, but did not rescue growth of nitrogen starved D. viridis (Supplementary Figure S1).

\section{Dunaliella Cells Grow on Four Amino Acids as a Sole Nitrogen Source}

Our screen revealed that compared to a nitrogen starvation control, cultures of $D$. viridis could reach high cell densities when supplemented with the amino acids Gln, His, Cys, and Trp (Figures 2, 4 and Table 2). The other 16 proteinogenic amino acids either had no observable effect on growth, or caused a small decrease in final cell density. However, glycine was an exception under one condition. When glycine $(5 \mathrm{mM})$ was mixed with $\mathrm{KNO}_{3}(5 \mathrm{mM})$ cultures had a final cell density and neutral lipid productivity nearly $50 \%$ greater than cultures grown with $\mathrm{KNO}_{3}$ alone (Supplementary Figure S2). This initial nitrogen 
TABLE 2 | Growth of four Dunaliella strains supplemented with GIn, Cys, His, and Trp.

\begin{tabular}{|c|c|c|c|c|}
\hline N Source & D. salina & D. viridis & D. tertiolecta & D. primolecta \\
\hline $\mathrm{KNO}_{3}(\mathrm{mBA})$ & $1.00 \pm 0.05^{* *}$ & $1.00 \pm 0.10^{* * *}$ & $1.00 \pm 0.03^{* * *}$ & $1.00 \pm 0.10^{* * *}$ \\
\hline Glutamine & $0.94 \pm 0.02^{* *}$ & $0.89 \pm 0.04^{* * *}$ & $0.94 \pm 0.06^{* * *}$ & $0.65 \pm 0.03^{* * *}$ \\
\hline Cysteine & $0.75 \pm 0.06^{*}$ & $0.59 \pm 0.10^{* * *}$ & $0.71 \pm 0.04^{* * *}$ & $0.52 \pm 0.10^{* * *}$ \\
\hline Histidine & $0.76 \pm 0.06^{*}$ & $0.36 \pm 0.08^{* * *}$ & $0.53 \pm 0.07$ & $0.33 \pm 0.03^{* * *}$ \\
\hline Tryptophan & $0.85 \pm 0.06^{*}$ & $0.62 \pm 0.03^{* * *}$ & $\mathrm{~N} / \mathrm{A}$ & $0.45 \pm 0.08^{* * *}$ \\
\hline $\mathrm{mBA}-\mathrm{N}$ & $0.62 \pm 0.06$ & $0.17 \pm 0.02$ & $0.46 \pm 0.01$ & $0.24 \pm 0.02$ \\
\hline
\end{tabular}

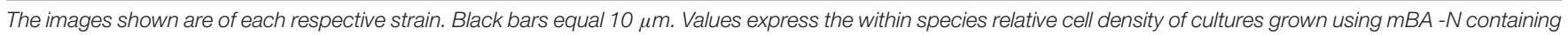

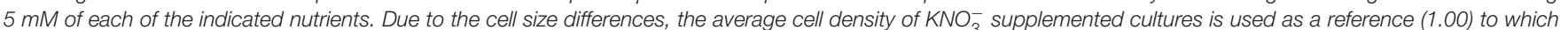

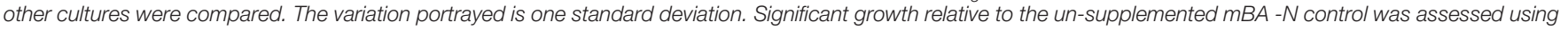
a two-tailed paired Student's $t$-Test at $p \leq 0.05\left(^{*}\right), p \leq 0.01\left(^{* *}\right)$, and $p \leq 0.001\left(^{* *}\right)$. Four biological replicates were used for analysis.

source screen was expanded to include three other species of Dunaliella (D. salina, D. tertiolecta, D. primolecta). We found that all four species consistently reached higher cell densities than nitrogen starvation controls when supplied with Gln, His, Cys, Trp (Table 2). Just as for D. viridis, the other 16 proteinogenic amino acids had no observable effect on growth.

\section{The Availability of Nitrogen and Supplementation of Amino Acids Alters Metabolite Accumulation of Dunaliella spp. in a Species Specific Manner}

There were differences in the level of metabolites accumulated by cells of each Dunaliella species, which was significant both when comparing between species and when comparing nitrogen supplementation treatments (Figure 4). While nitrogen starvation was generally associated with lower cell densities and decreased chlorophyll content, nitrogen-starved D. salina and $D$. viridis accumulated different levels of carbon storage metabolites and protein (Figure 4). Nitrogen-starved cultures of both $D$. salina and $D$. viridis accumulated higher amounts of neutral lipids on a cell basis, but $D$. viridis cells accumulated about five times more neutral lipids than $\mathrm{KNO}_{3}^{-}$fed controls. Cells of $D$. salina accumulated about three times more carbohydrates under nitrogen starvation, while carbohydrate levels were unchanged in cells of $D$. viridis subjected to the same treatment (Figure 4). Cell protein abundance was significantly lower during nitrogen starvation in $D$. salina, but not in $D$. viridis.

Gln, His, Cys and Trp supplementation altered the metabolite profiles of Dunaliella in a species specific manner (Figure 4). While supplementation with each of four amino acids recovered the growth of Dunaliella, the color of these cultures was often different compared to $\mathrm{KNO}_{3}$ controls (Supplementary Figure S3). This color change was obvious even when comparing cultures of equivalent cell density. Consequently, each amino acid altered the metabolite profile of species in ways that were unique from both controls and other amino acids.

Gln supplementation yielded final cell densities and cell protein content that were nearly as high as a $\mathrm{KNO}_{3}$ control (Figure 4). However, for both $D$. viridis and D. salina the chlorophyll content in Gln supplemented cultures tended to be lower, and Gln supplemented cultures D. viridis were visibly yellow (Supplementary Figure S3). Compared to $\mathrm{KNO}_{3}$ controls, Gln supplemented cultures had almost double cellular carbohydrate content and consequently produced at least 50\% more carbohydrates in total. Gln was also associated with a twofold higher level of cellular triacylglycerol production in D. viridis (Figure 4).

Although cultures supplemented with Cys did not grow as well as those supplemented with Gln, they accumulated similar levels of metabolites (Figure 4). Like Gln cultures, Cys supplemented cultures were also visibly yellow (Supplementary Figure S3). Neutral lipids, carbohydrates, and chlorophyll were present at equivalent levels in both treatments in D. viridis. However, Cys supplementation produced higher cell protein content than Gln or $\mathrm{KNO}_{3}$ cultures (Figure 4).

The growth rate of Dunaliella cultures supplemented with His remained low for all tested species (Table 2). Protein levels of His-fed cultures were only marginally higher than nitrogen-starved controls (Figure 4). As was the case for Gln and Cys supplementation, His-supplemented cultures had low chlorophyll content, giving rise to a yellowish appearance (Supplementary Figure S3).

Trp added to growth media produced a vibrant orange color after incubation for several days and exposure to light (Supplementary Figure S3). This effect also occurred in sterile media. Trp-supplemented cultures were often contaminated with bacteria [data not shown], which was never seen for the other amino acids. Data could only be obtained for cultures that had undergone a rigorous selection procedure to isolate cultures free of contaminating bacteria (Supplemental Methods). Cultures supplemented with Trp were unique in that both protein and chlorophyll levels tended to be highest in these treatments (Figure 4). While Trp supplementation marginally increased the carbohydrate content of D. salina, it reduced the neutral lipid content of $D$. viridis cells to $31 \%$ of $\mathrm{KNO}_{3}$ fed cells. Trp fed cultures produced one fifth the volume of neutral lipids compared to $\mathrm{KNO}_{3}$ controls. This effect was not observed in other species, but occurred even if $D$. viridis was simultaneously cultured with $\mathrm{KNO}_{3}$ and Trp (Supplementary Figure S2). 

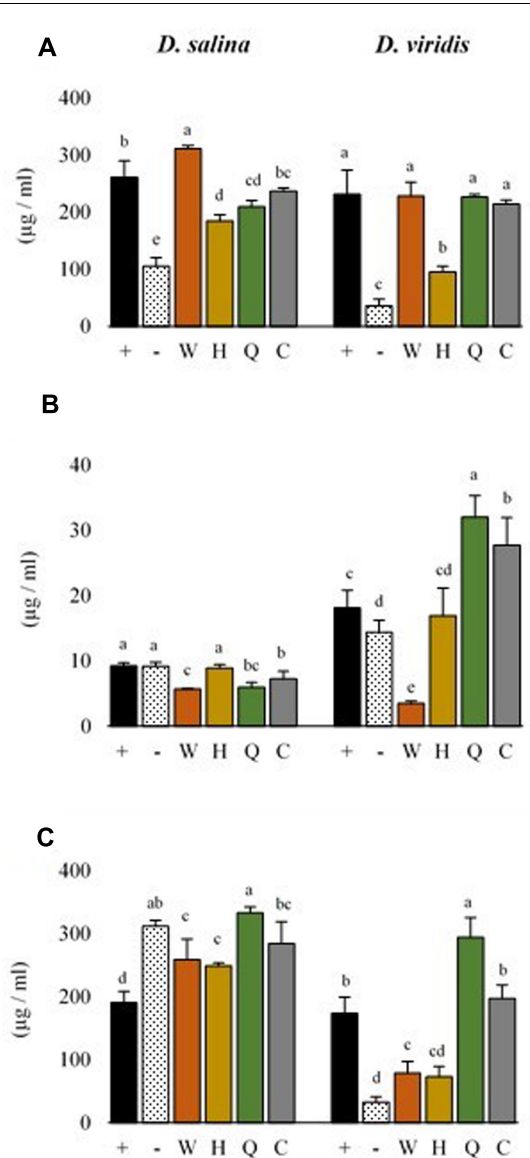

D

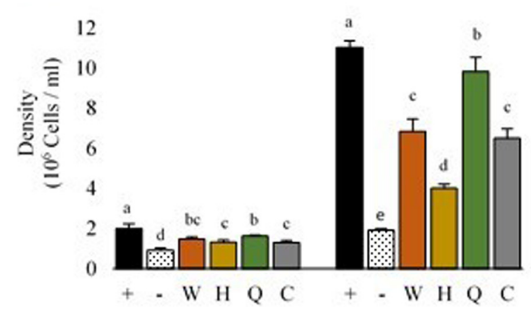

$\begin{array}{lll}\text { E D. salina } & \text { D. viridis }\end{array}$

$200 \%$

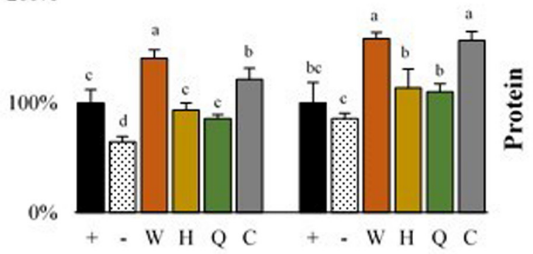

$\mathbf{F}$

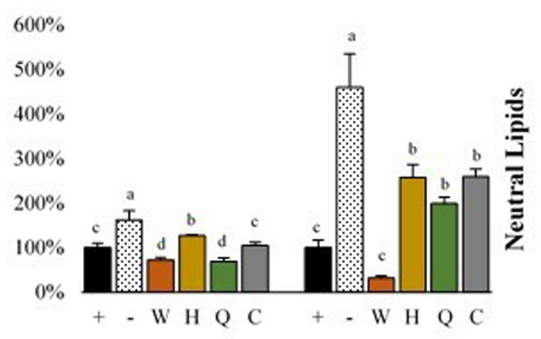

G

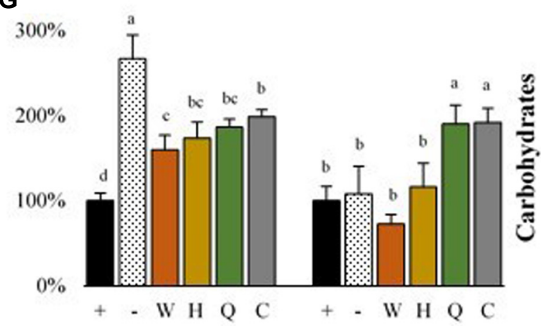

H

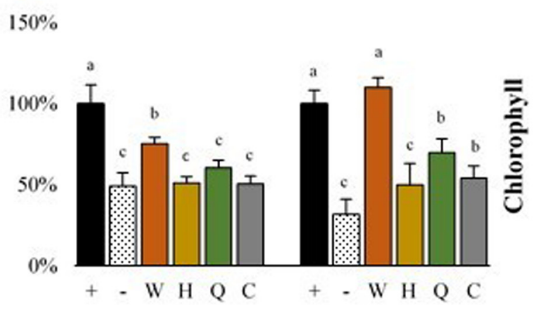

FIGURE 4 | Metabolite productivity and content of $D$. salina and D. viridis. Abbreviations: + (mBA), - (mBA -N), W (tryptophan), H (histidine), Q (glutamine), C (cysteine). Volumetric productivity (left column) of soluble protein (A), neutral lipids (B), total carbohydrates (C), and cell density (D) of cultures grown for $144 \mathrm{~h}$. The cell content of soluble protein (E), neutral lipids (F), total carbohydrates (G), and chlorophyll (H) is expressed relative to KNO ${ }_{3}^{-}$supplemented cultures (mBA), which are used as a reference (100\%). Error bars represent one standard deviation. Statistically significant population groupings are indicated (a,b,c,d,e; Tukey's HSD; $\alpha \leq 0.05$ ). Four biological replicates were used for analysis.

\section{Evidence of Amino Acid Assimilation Routes}

The mechanism by which Dunaliella spp. are able to obtain nitrogen from the amino acids His, Gln, Trp, and Cys was investigated using the ecotype $D$. viridis as a model. Routes supported by prior literature include transport of amino acids across the cell membrane and recovery of $\mathrm{NH}_{4}{ }^{+}$separated from amino acids either by abiotic oxidation chemistry or the activity of a deaminating enzyme (Kirk and Kirk, 1978a; Abraham and
Podell, 1981; Palenik and Morel, 1990, 1991; Gracanin et al., 2009).

The uptake of radiolabeled Gln, cystine, and His by $D$. viridis was measured over a period of $120 \mathrm{~min}$ (Figure 5A). Cystine was used as a proxy for Cys because of the relative instability of Cys, which rapidly oxidizes to cystine in aqueous solution (Kendall and Nord, 1926). No uptake of cystine or Gln was detected, only His was significantly taken up. This was true even if the culture used for the uptake assay was nitrogen-starved for $72 \mathrm{~h}$ prior to 


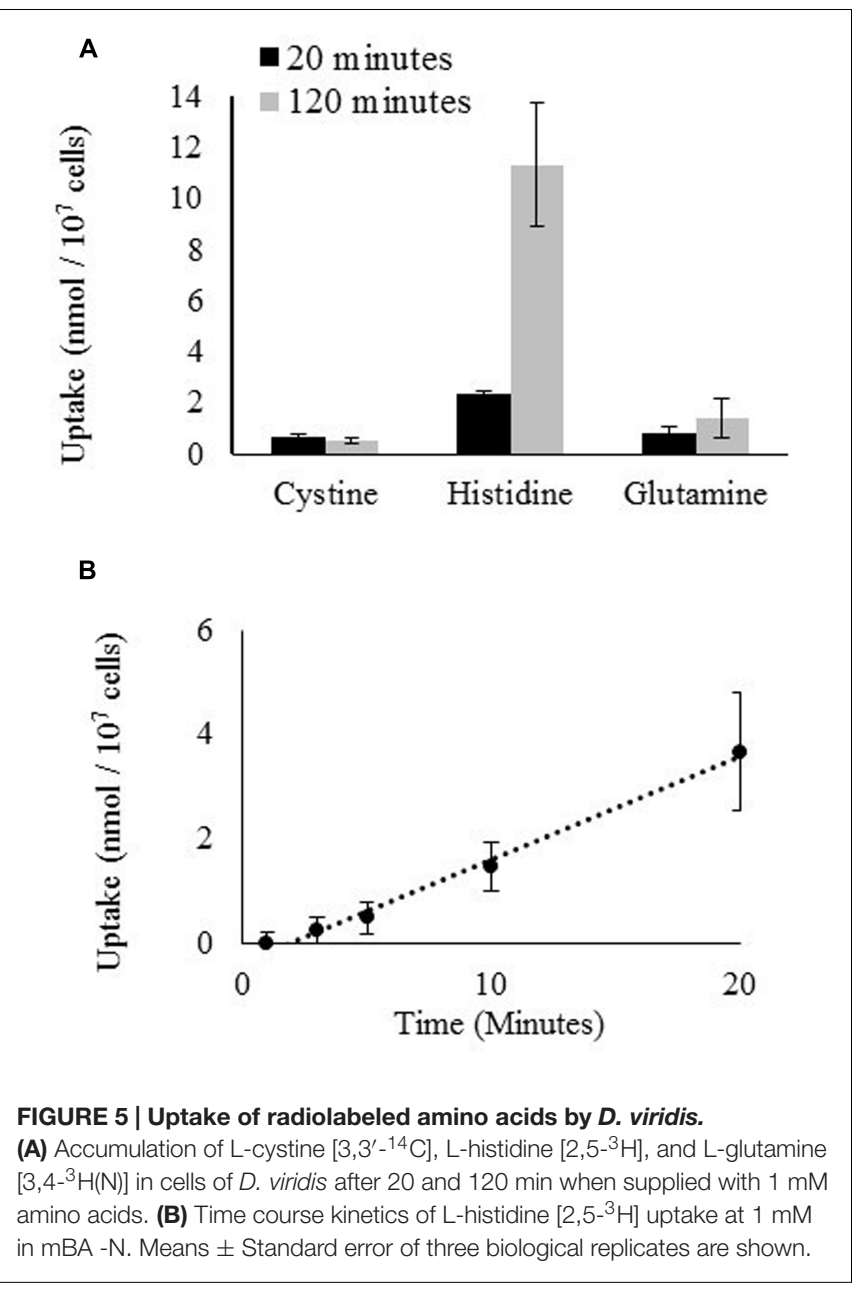

the assay (Data not shown). The uptake for radiolabeled His was approximately linear over a period of $20 \mathrm{~min}$ (Figure 5B).

The degree of $\mathrm{NH}_{4}{ }^{+}$production by sterile His, Gln, Glu, Cys, and Trp-containing media was assessed using the same light and temperature conditions that are used for growth of Dunaliella cultures. Gln, Cys, and Trp media generated increasing $\mathrm{NH}_{4}{ }^{+}$ concentrations over time (Figure 6). In contrast, His-containing media gave an initially high signal, but the apparent $\mathrm{NH}_{4}{ }^{+}$ concentration of this media did not significantly change over time. Glu was used as a control and did not produce any detectable amount of free $\mathrm{NH}_{4}{ }^{+}$.

The NMR spectra of media was used to ascertain the fate of Gln in culture. Spent media from $D$. viridis cultivated with mBA - N containing Gln revealed that peaks corresponding to Gln were present at all time points, and that the absolute value of these peaks did not change significantly (Figure 7). However, a set of peaks corresponding to pyroglutamate appear prominently after $24 \mathrm{~h}$, and the strength of this signal increased at $48 \mathrm{~h}$ (Figure 7). The estimated rate of pyroglutamate formation in this experiment was considerably higher than that obtained for the abiotic production of $\mathrm{NH}_{4}{ }^{+}$from Gln-containing media (Figures 6, 7).

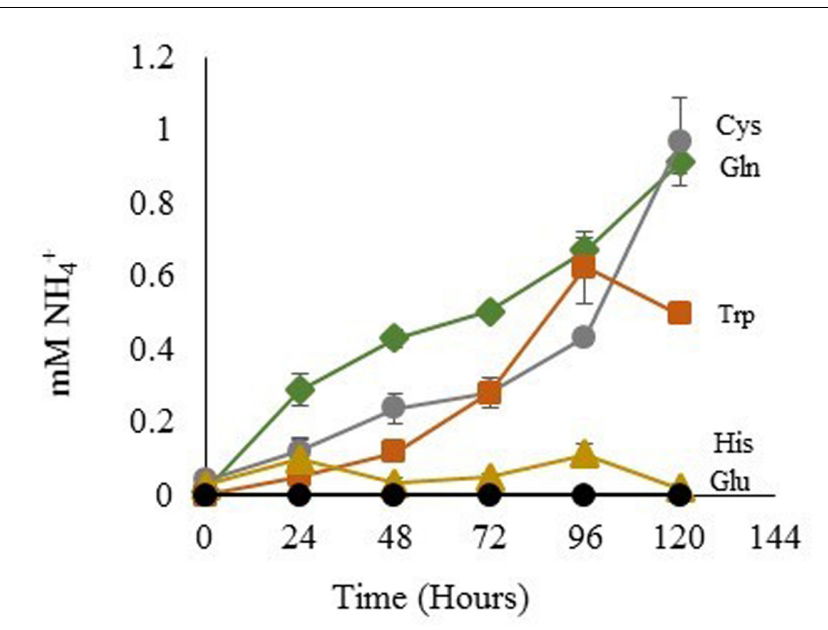

FIGURE 6 | $\mathrm{NH}_{4}{ }^{+}$Released from amino acids in sterile media. Glutamic Acid $\bullet$; tryptophan $\mathbf{\square}$; histidine $\Delta$; glutamine $\bullet$; cysteine $\bullet$. Means \pm Standard Deviation of three independent replicates are shown.

\section{Amino Acid Content of Dunaliella viridis}

The amino acid content of $D$. viridis was obtained in order to ascertain what proportion of the biomass could be recycled using Gln, His, Trp, and Cys as fertilizer supplementation. There was little variation in the overall amino acid content of $D$. viridis even between nitrogen-depleted and $\mathrm{KNO}_{3}^{-}$supplemented cultures (Table 3). The sum of relative Gln, His, Trp, and Cys fractions was at most $16 \%$ of the total amino acid fraction.

\section{DISCUSSION}

We surveyed the potential of using amino acids and other organic and inorganic nitrogen sources to support growth of four species from the genus Dunaliella. D. viridis was the only species that uniquely did not use urea as a nitrogen source, likely because the dumsii ecotype used in this study does not possess a urea transporter or an allophanate hydrolase (Table 1). In contrast to prior reports, we found that Dunaliella spp. are susceptible to $\mathrm{NH}_{4}{ }^{+}$toxicity above $1 \mathrm{mM}$ (Figure 3 ).

Four amino acids supported growth of Dunaliella spp.: Gln, Cys, His, and Trp. Based on their existence in other algae, we investigated three potential routes by which Dunaliella spp. could acquire nitrogen from Gln, Cys, His, and Trp (Figure 8). No evidence was obtained that supports the existence of an extracellular amino acid oxidase in Dunaliella spp., and only His showed evidence of uptake across the cell membrane. Gln, Cys, and Trp release $\mathrm{NH}_{4}{ }^{+}$via an abiotic process that Dunaliella spp. cells probably transport and utilize as nitrogen source.

\section{Dunaliella viridis Lacks the Necessary Genes for both Urea Transporters and Allophanate Hydrolase}

Dunaliella viridis could not use urea as a nitrogen source (Figure 2 and Table 1). This is in contrast to other Dunaliella 

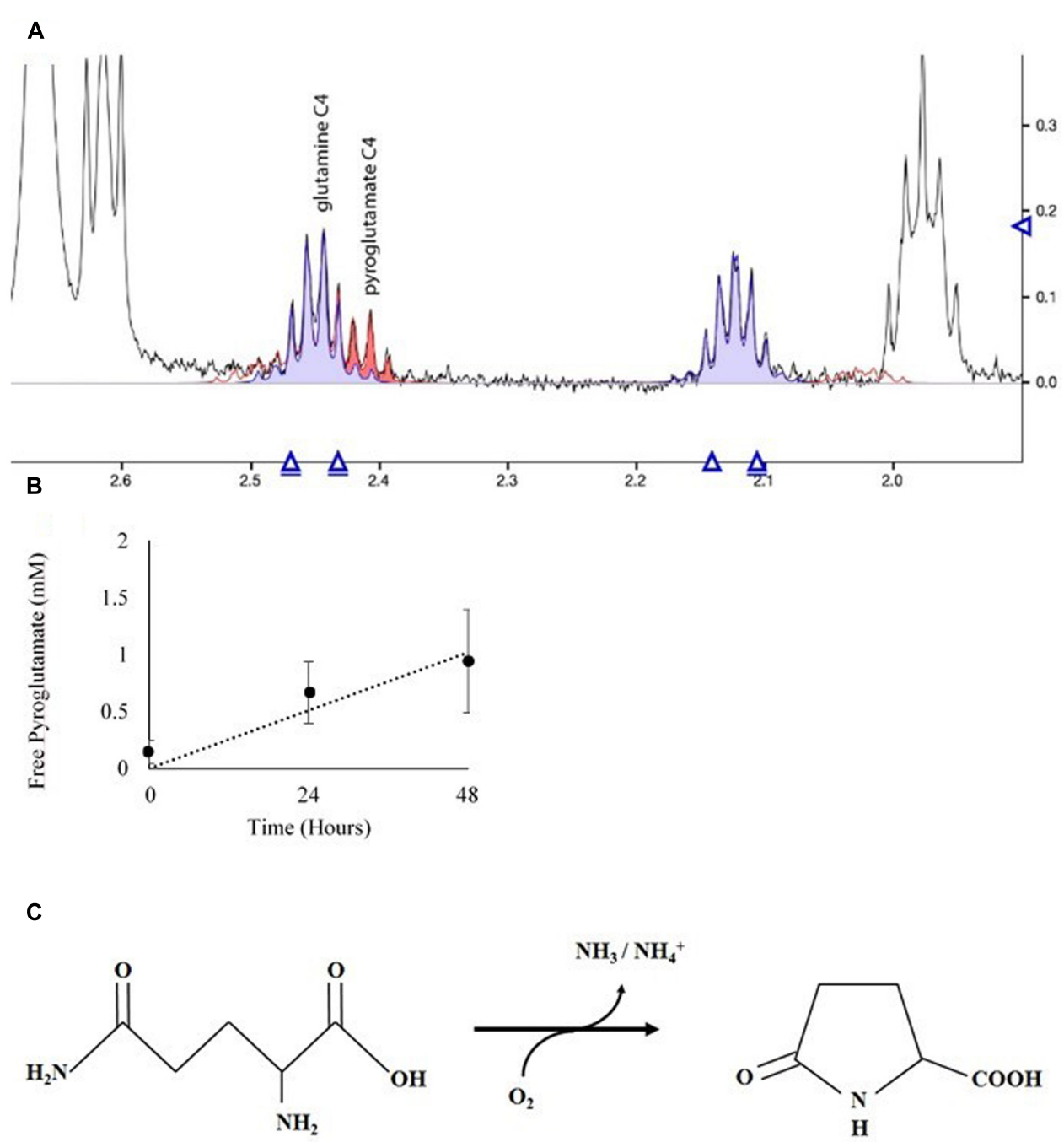

FIGURE 7 | Spectral analysis of spent growth medium containing glutamine. (A) Portion of the NMR spectrum delineating the C4 position of glutamine and its cyclic breakdown compound, pyroglutamate. (B) Time course of pyroglutamate formation in spent media. Means \pm Standard Deviation of three independent replicates are shown. (C) Oxidation reaction diagram of glutamine in aqueous solution under oxidizing conditions.

spp., which recover growth when supplemented with urea (Table 1; Hellio and Le Gal 1998, 1999). The use of urea as a nitrogen source requires at least two components: urea uptake via a membrane transport protein and subsequent enzymatic degradation into $\mathrm{HCO}_{3}^{-} / \mathrm{CO}_{2}$ and $\mathrm{NH}_{4}{ }^{+}$(Fan et al., 2012). $\mathrm{NH}_{4}{ }^{+}$released by these two activities can then be assimilated via the GS-GOGAT pathway. We therefore probed the genomes of each Dunaliella species for the presence of sequence encoding putative urea transporters, urease, urea carboxylase, and allophanate hydrolase. No predicted proteins similar to urea transporters could be detected in the available genomic resources for D. viridis (Table 1). However, sequences putatively coding for these transporters could be identified in the other species of Dunaliella. The surveyed Dunaliella species do not contain any coding sequences for urease (Table 1). D. salina, D. tertiolecta, and D. primolecta contain sequences for urea carboxylase and allophanate hydrolase, while $D$. viridis only contains a sequence for urea carboxylase (Table 1). D. salina, $D$. tertiolecta, and D. primolecta grow when supplemented with urea as a sole nitrogen source and possess three necessary proteins that enable urea acquisition and metabolism. In contrast, this particular ecotype of $D$. viridis likely cannot utilize urea because it does not possess a transporter to carry urea across the cell membrane for subsequent assimilation. Even if D. viridis had an unknown protein capable of urea transport, it could convert urea to allophanate, but could not complete the conversion to ammonium and bicarbonate unless it possesses an unknown or alternate enzyme rescuing the activity of allophanate hydrolase.

One caveat is that the genomic resources available for $D$. viridis are derived entirely from RNA sequencing. Urea transporter and allophanate hydrolase mRNAs may not have been captured in 
TABLE 3 | Amino acid content of $D$. viridis.

\begin{tabular}{|c|c|c|c|}
\hline Amino Acid & mBA & $\begin{array}{c}\mathrm{mBA}-\mathrm{N}+ \\
0.5 \mathrm{mM} \mathrm{NH}_{4}^{+}\end{array}$ & mBA -N \\
\hline His & $1.30 \% \pm 0.04$ & $0.46 \% \pm 0.21$ & $1.61 \% \pm 0.06$ \\
\hline Ser $^{1}$ & $8.03 \% \pm 0.43$ & $9.83 \% \pm 1.33$ & $8.49 \% \pm 0.51$ \\
\hline Arg & $4.20 \% \pm 0.18$ & $3.99 \% \pm 0.59$ & $4.09 \% \pm 0.16$ \\
\hline Gly & $9.72 \% \pm 0.72$ & $8.69 \% \pm 1.19$ & $8.70 \% \pm 0.31$ \\
\hline $\mathrm{Asp} / \mathrm{Asn}^{2}$ & $10.26 \% \pm 0.80$ & $10.07 \% \pm 1.41$ & $9.60 \% \pm 0.39$ \\
\hline Gln/Glu² & $13.91 \% \pm 0.92$ & $13.68 \% \pm 1.97$ & $13.06 \% \pm 0.56$ \\
\hline Thr & $4.73 \% \pm 0.28$ & $4.89 \% \pm 0.72$ & $5.06 \% \pm 0.18$ \\
\hline Ala & $12.38 \% \pm 0.95$ & $12.31 \% \pm 1.45$ & $12.16 \% \pm 0.41$ \\
\hline Pro & $5.30 \% \pm 0.44$ & $4.11 \% \pm 0.44$ & $5.61 \% \pm 0.18$ \\
\hline Cys & $0.52 \% \pm 0.18$ & $0.22 \% \pm 0.07$ & $0.29 \% \pm 0.02$ \\
\hline Lys & $6.22 \% \pm 0.36$ & $6.07 \% \pm 0.79$ & $6.16 \% \pm 0.23$ \\
\hline Tyr & $3.51 \% \pm 0.16$ & $4.57 \% \pm 0.51$ & $3.45 \% \pm 0.13$ \\
\hline Met & $1.77 \% \pm 0.18$ & $1.99 \% \pm 0.25$ & $1.94 \% \pm 0.07$ \\
\hline Val & $4.66 \% \pm 0.14$ & $5.22 \% \pm 1.16$ & $5.21 \% \pm 0.21$ \\
\hline lle & $2.75 \% \pm 0.09$ & $2.56 \% \pm 1.02$ & $3.10 \% \pm 0.11$ \\
\hline Leu & $7.36 \% \pm 0.46$ & $7.81 \% \pm 1.27$ & $7.96 \% \pm 0.30$ \\
\hline Phe & $3.00 \% \pm 0.18$ & $3.22 \% \pm 0.52$ & $3.30 \% \pm 0.11$ \\
\hline Trp & $0.39 \% \pm 0.02$ & $0.30 \% \pm 0.01$ & $0.20 \% \pm 0.06$ \\
\hline $\begin{array}{l}\text { Sum of His, } \\
\text { GIn/Glu, Cys, Trp }\end{array}$ & $16.11 \% \pm 1.16$ & $14.67 \% \pm 2.27$ & $15.16 \% \pm 0.69$ \\
\hline
\end{tabular}

${ }^{1} A$ major component of $m B A$ is tris, which eluted at a retention time close to serine, preventing accurate quantification. ${ }^{2}$ This data does not differentiate between glutamine and glutamic acid, or between asparagine and aspartic acid due to conversion during hydrolysis. Bolded values in this table highlight the amino acids most relevant to the text of this study.

the samples used for sequencing. We probed for the presence of urea transporter and allophanate hydrolase genes in the genomic DNA of $D$. viridis using consensus primers derived from the sequence of other Dunaliella spp. No putative urea transporter or allophanate hydrolase genes were amplified from $D$. viridis genomic DNA using D. salina, D. tertiolecta, and D. primolecta genomic DNA as positive controls (Data not shown). It is therefore highly unlikely that $D$. viridis possesses sequence coding for these two genes.

Urea carboxylase, allophanate hydrolase, and a urea transporter are grouped sequentially together within the D. salina genome ${ }^{8}$. This gene arrangement is also reflected on chromosome 8 of the $C$. reinhardtii genome (Merchant et al., 2007) and scaffold 3 of Volvox carteri (Prochnik et al., 2010), both species within the Chlamydomonadales order along with Dunaliella. If this syntenic relationship is conserved within the Chlamydomonadales order, this block of genes may have been deleted in $D$. viridis.

\section{$\mathrm{NH}_{4}{ }^{+}$Toxicity Varies with Experimental Methodology}

Although $\mathrm{NH}_{4}{ }^{+}$is a useful source of nitrogen for photosynthetic organisms, it is also toxic at high concentrations. $\mathrm{NH}_{4}{ }^{+}$toxicity is due to the decoupling effect of $\mathrm{NH}_{4}{ }^{+} / \mathrm{NH}_{3}$ equilibrium, which can disturb membrane proton and charge gradients (Krogmann

${ }^{8}$ http://phytozome.jgi.doe.gov/ et al., 1959). Surprisingly, $\mathrm{NH}_{4}^{+}$supplementation of the Dunaliella cultures used in this study is toxic at concentrations less than previously reported to be suitable ( $5 \mathrm{mM}$ ) (Figure 3; Giordano et al., 1994; Giordano, 1997). Instead, we found growth maxima for some Dunaliella spp. at $1 \mathrm{mM} \mathrm{NH}_{4} \mathrm{Cl}$, with higher concentrations causing inhibition of growth or cell death. It is therefore necessary to understand what factors contribute to the ability of some Dunaliella spp. to tolerate this nutrient better than others. However, there are several key differences in the methods used to cultivate Dunaliella spp. between our study and those prior that may explain this discrepancy.

Acclimation of Dunaliella spp. to the presence of $\mathrm{NH}_{4}{ }^{+}$ may affect the ability of these organisms to resist gradient decoupling effects. Dunaliella spp. have a long life cycle (0.47 1.22 divisions per $24 \mathrm{~h}$ ) (Oren, 2005), and therefore may require substantial time to shift genetic and protein machinery when first exposed to $\mathrm{NH}_{4}{ }^{+}$. Prior studies involving higher amounts of $\mathrm{NH}_{4}{ }^{+}$were materially different than ours in that the Dunaliella cultures used were acclimated to $\mathrm{NH}_{4} \mathrm{Cl}$ as a sole nitrogen source prior to the start of experimentation (Giordano et al., 1994; Giordano, 1997). In contrast, the cultures used in our study were grown using $\mathrm{KNO}_{3}$ as a sole nitrogen source prior to experimentation.

Another important factor affecting $\mathrm{NH}_{4}{ }^{+}$toxicity is the amount of headspace and airflow in the container used for algal cultivation. $\mathrm{NH}_{4}+/ \mathrm{NH}_{3}$ equilibrium increasingly favors the production of $\mathrm{NH}_{3}$, a volatile gas, under more basic conditions. The algal cultivation media used in this study begins neutral ( $\mathrm{pH}$ 7.5), but becomes basic $(\mathrm{pH} \mathrm{10)}$ after $72 \mathrm{~h}$. It is likely that as Dunaliella growth experiments progress, $\mathrm{NH}_{3}$ leaves the liquid phase of the cultures and lowers the effective $\mathrm{NH}_{4}{ }^{+}$ concentration in the media. Additionally, this process should proceed to an equilibrium given a limited space for gas expansion. As $\mathrm{NH}_{3}$ volatilizes out of liquid over time and occupies the headspace of its container, $\mathrm{NH}_{4}{ }^{+} / \mathrm{NH}_{3}$ equilibrium will be further driven toward $\mathrm{NH}_{3}$ production, likely lowering the effective $\mathrm{NH}_{4}{ }^{+}$concentration. This means that the headspace of its cultivation vessel likely has a large effect on the $\mathrm{NH}_{4}{ }^{+} / \mathrm{NH}_{3}$ equilibrium and therefore the effective $\mathrm{NH}_{4}{ }^{+}$concentration. Compared to other studies using $\mathrm{NH}_{4}{ }^{+}$supplementation in Dunaliella growth experiments, the 12 well tissue culture plates used in this study have less headspace. It is therefore reasonable to assume that the reason our cultures were more susceptible to $\mathrm{NH}_{4}{ }^{+}$toxicity was that they were subjected to higher effective levels of $\mathrm{NH}_{4}{ }^{+}$.

\section{GIn, Cys, and Trp Supply Nitrogen via the Release and Assimilation of $\mathrm{NH}_{4}{ }^{+}$}

Gln and Cys support growth of Dunaliella spp., but also increase the amount of carbon storage metabolites of cells compared to $\mathrm{KNO}_{3}$ fertilizer controls. It is unlikely to be the case that Dunaliella spp. can access or assimilate the carbon from Gln and Cys, as we found no evidence that these amino acids cross the cell membrane. Therefore, one likely reason for increased carbon storage is that Gln and Cys actually supply $\mathrm{NH}_{4}{ }^{+}$via their oxidative degradation, which is a more efficient source of 


\section{Pathways of Nitrogen Acquisition from Amino Acids}

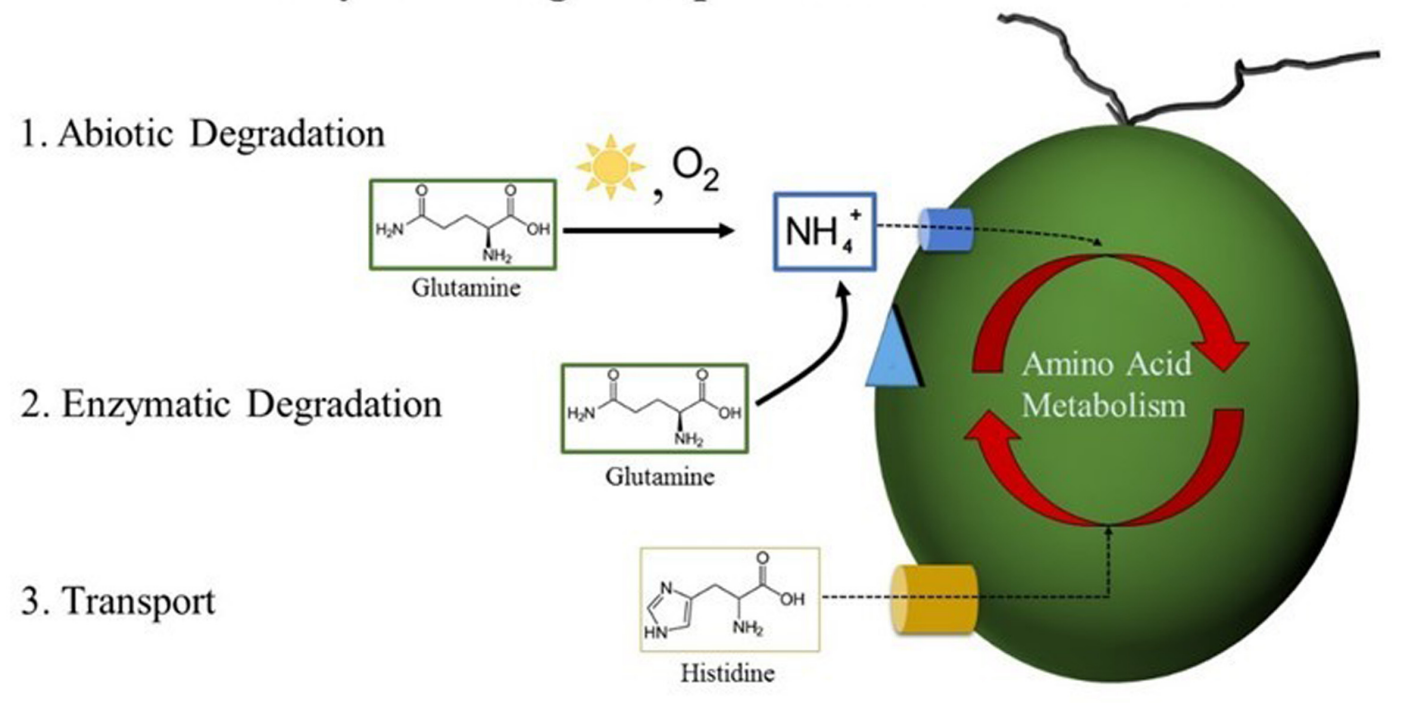

FIGURE 8 | Pathways of nitrogen acquisition from amino acids by Dunaliella spp. Postulated routes by which nitrogen from amino acids could be acquired by Dunaliella spp. from the growth medium. (1) Abiotic degradation resulting in the production of $\mathrm{NH}_{4}^{+}$can occur via nucleophilic attack of primary amines by atmospheric oxygen catalyzed by the presence of heat and light. Released $\mathrm{NH}_{4}{ }^{+}$can cross the cell membrane via a transport protein into the cell where it is assimilated via the GS-GOGAT pathway. (2) Enzymatic degradation of amino acids could occur if a Dunaliella species possesses an enzyme similar to the LAO1 protein of C. reinhardtii or another similar protein. This pathway would in effect release $\mathrm{NH}_{4}{ }^{+}$, which would be assimilated as in pathway 1. (3) Transport of amino acids across the cell membrane is mediated by a transporter. Once inside the cell, amino acids can be enzymatically degraded either by conversion into other amino acids via transamination or by the release and subsequent assimilation of $\mathrm{NH}_{4}{ }^{+}$.

nitrogen than $\mathrm{KNO}_{3}$. Cells must convert $\mathrm{KNO}_{3}$ to $\mathrm{NH}_{4}{ }^{+}$before nitrogen can be fixed to Glu via the GS-GOGAT cycle. This conversion process requires eight electrons, which are ultimately derived by light capture during photosynthesis. When $\mathrm{NH}_{4}{ }^{+}$is assimilated, the eight electrons that would have otherwise been needed for nitrate assimilation can be either utilized elsewhere, i.e., for carbon fixation, or the cell can reduce its rate of electron capture from water oxidation by lowering light harvesting activity and chlorophyll content. This is consistent with the observed levels of chlorophyll in Gln and Cys-supplemented cultures of both $D$. salina and $D$. viridis, which possessed significantly lower cellular chlorophyll levels than $\mathrm{KNO}_{3}$ fertilizer controls (Figure 4 and Supplementary Figure S3). Surprisingly, Gln and Cyssupplemented cultures produced higher cell concentrations of carbohydrates and neutral lipids while retaining similar amounts of protein compared to $\mathrm{KNO}_{3}$ controls. $\mathrm{NH}_{4}{ }^{+}$utilization is consistent with these metabolic effects, as this scenario allows that less electron capture could exist simultaneously with increased carbon capture.

Although Trp releases $\mathrm{NH}_{4}{ }^{+}$in solution like Cys and Gln, Trp supplementation resulted in uniquely elevated chlorophyll and protein levels as well as diminished neutral lipid content in $D$. viridis. These cultures were also commonly susceptible to contamination by bacteria, unlike other nutrient regimes we tested. Trp is also unique because it degrades into a variety of products due to light catalyzed oxidation of the pyrrole ring (Gracanin et al., 2009). This process is fast enough to be visually apparent, as cultures were visibly orange after as little as $24 \mathrm{~h}$.
Therefore, in addition to $\mathrm{NH}_{4}{ }^{+}$, there remains the possibility that one of many Trp degradation products or Trp itself is sensed or acquired by Dunaliella spp.

\section{Extracellular Enzymatic Release of $\mathrm{NH}_{4}{ }^{+}$ from Amino Acids Unlikely to Occur in Dunaliella spp.}

Extracellular deamination of amino acids by an enzyme is known to occur in microalgae (Munoz-Blanco et al., 1990; Palenik and Morel, 1990, 1991; Piedras et al., 1992; Vallon et al., 1993). Although there was no prior evidence for their existence in Dunaliella spp., we did not rule out the possibility that at least one of those enzymes was present and active. Dunaliella spp. are in the same Order as $C$. reinhardtii, which possesses a nonspecific L-amino acid oxidase (LAO1) located in the periplasmic space that deaminates a wide range of amino acids, releasing $\mathrm{NH}_{4}{ }^{+}$and corresponding keto-acids (Munoz-Blanco et al., 1990; Piedras et al., 1992; Vallon et al., 1993). We probed the genomes of four species of Dunaliella and could not find any protein-coding genes of significant similarity to LAO1 (Data not shown). The fact that Dunaliella cells grew only in the presence of amino acids subject to abiotic deamination does not support the hypothesis of the existence of an amino acid oxidase. Additionally, our NMR data reveal that cultures of glutamine-fed D. viridis form pyroglutamate outside the cell (Figure 7). If activity analogous to LAO1 existed we expect to instead find a signal corresponding to 2-keto-glutaramic acid. 


\section{Histidine Transport and Use Is Inefficient in Dunaliella spp.}

Uptake of His has now been demonstrated in two species of Dunaliella and appears to support growth in each of the species tested (Table 2 and Figure 5; Hellio and Le Gal 1998, 1999). We therefore speculate that His uptake and utilization may be a general feature of this genus. Although His is transported across the cell membrane, His supplementation conferred little improvement in growth or accumulation of major carbon or nitrogen metabolites over cultures that were starved for nitrogen. This is surprising, as transported His should functionally supply nitrogen and carbon via conversion by histidine ammonia lyase. However, the kinetics of His uptake, the identity of the transporting protein, and the mechanism of transport are unknown. This situation is intriguing because a parallel situation exists in the model alga $C$. reinhardtii. C. reinhardtii efficiently transports only one amino acid, arginine, which like histidine is positively charged, and the identity and mechanism of transport and assimilation of arginine are unknown. This similarity might yield an evolutionary insight if the respective transport mechanisms could be identified.

It is unlikely that His is able to supply nitrogen via enzymatic or abiotic degradation outside the cell, because light catalyzed degradation of His does not yield free $\mathrm{NH}_{4}{ }^{+}$, but aspartate and urea (Tomita et al., 1969). However, aspartate and urea do not support growth of $D$. viridis. Therefore, only His itself could supply nitrogen to cells of $D$. viridis. Additionally, His supplementation only marginally improved growth even in cultures that can use urea as a nitrogen source.

\section{CONCLUSION}

Gln, Cys, His, and Trp supports growth of Dunaliella spp. but are currently an insufficient means of nitrogen recycling from spent biomass. These four amino acids constitute at most $16 \%$ of the proteinaceous amino acid pool (Table 3) in D. viridis, and this value is likely inflated as our data does not distinguish values for Glu from Gln. Furthermore, the use of His only marginally improves growth and the use of Trp presents a contamination risk.

The fact that the same four proteinogenic amino acids consistently enabled growth of Dunaliella regardless of species is knowledge transferable to other work in the development of algal bioproducts. The release of $\mathrm{NH}_{4}{ }^{+}$from Gln, Trp, and Cys explains part of this consistency, as all Dunaliella, and indeed most photosynthetic microorganisms can use $\mathrm{NH}_{4}{ }^{+}$as a nitrogen source. Consequently, we predict that any alga which can use $\mathrm{NH}_{4}{ }^{+}$as a nitrogen source should also grow when supplemented

\section{REFERENCES}

Abraham, G. N., and Podell, D. N. (1981). "Pyroglutamic acid," in The Biological Effects of Glutamic Acid and its Derivatives, ed. V. A. Najjar (Dordrecht: Springer), 181-190. doi: 10.1007/BF00235695 with Gln, Trp, or Cys. Another implication is that like anaerobic digestion and hydrothermal liquefaction, the in vitro digestion scheme forming the basis of this work (Figure 1) must consider the abundance and impact of ammonium generated from abiotic amino acid degradation. Given this state, it would appear to be simpler to digest Dunaliella biomass using conventional means and recycle nitrogen as $\mathrm{NH}_{4}{ }^{+}$. However, if Dunaliella or another alga could use whole amino acids as both a carbon and nitrogen source the impact of $\mathrm{NH}_{4}{ }^{+}$would be reduced.

We had assumed that there would be variation in the use of amino acids between the Dunaliella species as these species are from different geographic areas of the world. However, the limited use of amino acids is not unique to Dunaliella, or to marine or halophilic microalgae generally. This yields an opportunity for genetic optimization, where transgenic Dunaliella or other algae expressing recombinant amino acid transporters or extracellular deaminating enzymes may allow greater usage of amino acid nitrogen.

Amino acid proportion of D. viridis cultivated for $144 \mathrm{~h}$ determined by UPLC-MS. Values above are expressed as the relative percentage of the total amino acid content of cultures. These values include both free amino acids and hydrolyzed total protein. The variation portrayed is one standard deviation. Values are derived from three biological replicates.

\section{AUTHOR CONTRIBUTIONS}

CM, JM, GP, and HS were involved in the conception and design of this project. CM, JD, SJ, CZ, DY, NK, and AT were involved in collection and assembly of data. CM, CZ, AT, JM, GP, and HS were involved in the analysis and interpretation of the data. All authors were involved in the drafting of this article. CM, JD, JM, GP, and HS were responsible for critical revision of the article for important intellectual content. All authors were involved in final approval of the article.

\section{ACKNOWLEDGMENT}

This work was supported by a NSF Emerging Frontiers in Research and Innovation (EFRI) grant [Award Abstract \#1332341].

\section{SUPPLEMENTARY MATERIAL}

The Supplementary Material for this article can be found online at: http://journal.frontiersin.org/article/10.3389/fpls.2017.00847/ full\#supplementary-material

Arnon, D. I. (1949). Copper enzymes in isolated chloroplasts. polyphenoloxidase in Beta vulgaris. Plant Physiol. 24, 1-15. doi: 10.1104/pp.24.1.1

Asquith, R. S., and Hirst, L. (1969). The photochemical degradation of cystine in aqueous solution in the presence of air. Biochim. Biophys. Acta 184, 345-357. doi: 10.1016/0304-4165(69)90037-3 
Azov, Y., and Goldman, J. C. (1982). Free ammonia inhibition of algal photosynthesis in intensive cultures. Appl. Environ. Microbiol. 43, 735-739.

Ben-Amotz, A., Shaish, A., and Avron, M. (1989). Mode of action of the massively accumulated Beta-carotene of Dunaliella bardawil in protecting the alga against damage by excess irradiation. Plant Physiol. 91, 1040-1043. doi: 10.1104/pp.91. 3.1040

Biller, P., Ross, A. B., Skill, S. C., Lea-Langton, A., Balasundaram, B., Hall, C., et al. (2012). Nutrient recycling of aqueous phase for microalgae cultivation from the hydrothermal liquefaction process. Algal Res. 1, 70-76. doi: 10.1016/j.algal. 2012.02.002

Bobbink, R., Hicks, K., Galloway, J., Spranger, T., Alkemade, R., Ashmore, M., et al. (2010). Global assessment of nitrogen deposition effects on terrestrial plant diversity: a synthesis. Ecol. Appl. 20, 30-59. doi: 10.1890/08-1140.1

Borowitzka, M. A., and Siva, C. J. (2007). The taxonomy of the genus Dunaliella (Chlorophyta, Dunaliellales) with emphasis on the marine and halophilic species. J. Appl. Phycol. 19, 567-590. doi: 10.1007/s10811-007-9171-x

Cain, J. (1965). Nitrogen utilization in 38 freshwater chlamydomonad algae. Can. J. Bot. 43 1367-1378. doi: 10.1139/b65-146

Chen, M., Tang, H., Ma, H., Holland, T. C., Ng, K. Y., and Salley, S. O. (2011). Effect of nutrients on growth and lipid accumulation in the green algae Dunaliella tertiolecta. Bioresour. Technol. 102, 1649-1655. doi: 10.1016/j.biortech.2010.09. 062

Chen, Y., Cheng, J. J., and Creamer, K. S. (2008). Inhibition of Anaerobic Digestion Process: a Review. Bioresour. Technol. 99, 4044-4064. doi: 10.1016/j.biortech. 2007.01.057

Chisti, Y. (2008). Biodiesel from microalgae beats bioethanol. Trends Biotechnol. 26, 126-131. doi: 10.1016/j.tibtech.2007.12.002

Chisti, Y. (2013). Constraints to commercialization of algal fuels. J. Biotechnol. 167, 201-214. doi: 10.1016/j.jbiotec.2013.07.020

Cho, B.-H., and Le Gal, E. (1985). The amino acid transport systems of the autotrophically grown green alga Chlorella. Biochim. Biophys. Acta 821, 384-392. doi: 10.1016/0005-2736(85)90042-2

Crutzen, P. J., Mosier, A. R., Smith, K. A., and Winiwarter, W. (2008). N 2 O release from agro-biofuel production negates global warming reduction by replacing fossil fuels. Atmos. Chem. Phys. 8, 389-395. doi: 10.1007/978-3-31927460-7_12

Dewar, B. J., Keshari, K., Jeffries, R., Dzeja, P., Graves, L. M., and Macdonald, J. M. (2010). Metabolic assessment of a novel chronic myelogenous leukemic cell line and an imatinib resistant subline by $1 \mathrm{~h} \mathrm{nmr}$ spectroscopy. Metabolomics 6 439-450. doi: 10.1007/s11306-010-0204-0

Dubois, M., Gilles, K., Hamilton, J. K., Rebers, P. A., and Smith, F. (1956). Colorimetric method for determination of sugars and related substances. Anal. Chem. 28, 350-356. doi: 10.1021/ac60111a017

Elsey, D., Jameson, D., Raleigh, B., and Cooney, M. J. (2007). fluorescent measurement of microalgal neutral lipids. J. Microbiol. Methods 68, 639-642. doi: 10.1016/j.mimet.2006.11.008

Eppley, R. W., Coatsworth, J. L., and Solorzano, L. (1969). studies of nitrate reductase in marine phytoplankton. Limnol. Oceanogr. 14, 194-205. doi: 10.4319/lo.1969.14.2.0194

Erisman, J. W., Sutton, M. A., Galloway, J. N., Klimont, Z., and Winiwarter, W. (2008). How a century of ammonia synthesis changed the world. Nat. Geosci. 1, 636-639. doi: 10.1038/ngeo325

Fabregas, J., Abalde, J., Cabezas, B., and Herrero, C. (1989). changes in protein, carbohydrates and gross energy in the marine microalga Dunaliella tertiolecta (Butcher) by nitrogen concentrations as nitrate, nitrite and urea. Aquac. Eng. 8, 223-239. doi: 10.1016/0144-8609(89)90011-3

Fan, C., Chou, C. Y., Tong, L., and Xiang, S. (2012). Crystal structure of urea carboxylase provides insights into the carboxyltransfer reaction. J. Biol. Chem. 287, 9389-9398. doi: 10.1074/jbc.M111.319475

Finn, R. D., Coggill, P., Eberhardt, R. Y., Eddy, S. R., Mistry, J., Mitchell, A. L., et al. (2016). The Pfam protein families database: towards a more sustainable future. Nucleic Acids Res. 44, D279-D285. doi: 10.1093/nar/gkv1344

Fischer, W.-N., André, B., Rentsch, D., Krolkiewicz, S., Tegeder, M., Breitkreuz, K., et al. (1998). Amino acid transport in plants. Trends Plant Sci. 3, 188-195. doi: 10.1016/S1360-1385(98)01231-X

Galloway, J. N., Townsend, A. R., Erisman, J. W., Bekunda, M., Cai, Z., Freney, J. R., et al. (2008). Transformation of the nitrogen cycle: recent trends, questions, and potential solutions. Science 320, 889-892. doi: 10.1126/science.1136674
Garcia Alba, L., Vos, M. P., Torri, C., Fabbri, D., Kersten, S. R., and Brilman, D. W. (2013). Recycling nutrients in algae biorefinery. ChemSusChem 6, 1330-1333. doi: $10.1002 /$ cssc. 201200988

Georgianna, D. R., and Mayfield, S. P. (2012). exploiting diversity and synthetic biology for the production of algal biofuels. Nature 488, 329-335. doi: 10.1038/ nature11479

Giordano, M. (1997). Adaptation of Dunaliella Salina (Volvocales, Chlorophyceae) to growth on nh4 as the sole nitrogen source. Phycologia 36, 345-350. doi: 10.2216/i0031-8884-36-5-345.1

Giordano, M., Davis, J. S., and Bowes, G. (1994). Organic carbon release by Dunaliella Salina (Chlorophyta) under different growth conditions of Co2, nitrogen, and salinity. J. Phycol. 30, 249-257. doi: 10.1111/j.0022-3646.1994. 00249.x

Goldman, J. C., and Peavey, D. G. (1979). Steady-state growth and chemical composition of the marine chlorophyte Dunaliella tertiolecta in nitrogenlimited continuous cultures. Appl. Environ. Microbiol. 38, 894-901.

Gracanin, M., Hawkins, C. L., Pattison, D. I., and Davies, M. J. (2009). Singletoxygen-mediated amino acid and protein oxidation: formation of tryptophan peroxides and decomposition products. Free Radic. Biol. Med. 47, 92-102. doi: 10.1016/j.freeradbiomed.2009.04.015

Grobbelaar, J. U. (2004). "Algal nutrition mineral nutrition," in Handbook of Microalgal Culture: Biotechnology and Applied Phycology, ed. A. Richmond (Oxford: Blackwell Science), 95-115. doi: 10.1002/9780470995280.ch6

Hellio, C., and Le Gal, Y. (1998). Histidine utilization by the unicellular alga Dunaliella tertiolecta. Comp. Biochem. Physiol. Mol. Integr. Physiol. 119, 753-758. doi: 10.1016/S1095-6433(98)01011-3

Hellio, C., and Le Gal Y. (1999). Histidase from the unicellular green alga Dunaliella tertiolecta: purification and partial characterization. Eur. J. Phycol. 34, 71-78. doi: 10.1080/09670269910001736102

Huo, Y.-X., Wernick, D. G., and Liao, J. C. (2012). Toward nitrogen neutral biofuel production. Curr. Opin. Biotechnol. 23, 406-413. doi: 10.1016/j.copbio.2011. 10.005

Jena, U., Vaidyanathan, N., Chinnasamy, S., and Das, K. C. (2011). Evaluation of microalgae cultivation using recovered aqueous co-product from thermochemical liquefaction of algal biomass. Bioresour. Technol. 102, 3380-3387. doi: 10.1016/j.biortech.2010.09.111

Kendall, E. C., and Nord, F. F. (1926). Reversible oxidation-reduction systems of cysteine-cystine and reduced and oxidized glutathione. J. Biol. Chem. 69, 295-337.

Kirk, D. L. and Kirk, M. M. (1978a). Carrier-mediated uptake of arginine and urea by Chlamydomonas reinhardtii. Plant Physiol. 61, 556-560. doi: 10.1104/pp.61. 4.556

Kirk, M. M., and Kirk, D. L. (1978b). Carrier-mediated uptake of arginine and urea by Volvox carteri f. nagariensis. Plant Physiol. 61, 549-555. doi: 10.1104/pp.61. 4.549

Kojima, S., Bohner, A., and Von Wirén, N. (2006). Molecular mechanisms of urea transport in plants. J. Membr. Biol. 212, 83-91. doi: 10.1007/s00232-006-0868-6

Krogmann, D. W., Jagendorf, A. T., and Avron, M. (1959). Uncouplers of spinach chloroplast photosynthetic phosphorylation. Plant Physiol. 34, 272-277. doi: $10.1104 /$ pp.34.3.272

Lam, M. K., and Lee, K. T. (2012). Microalgae biofuels: a critical review of issues, problems and the way forward. Biotechnol. Adv. 30, 673-690. doi: 10.1016/j. biotechadv.2011.11.008

Latorella, A. H., Bromberg, S. K., Lieber, K., and Robinson, J. (1981). Isolation and partial characterization of nitrate assimilation mutants of Dunaliella tertiolecta (Chlorophyceae) 1. J. Phycol. 17, 211-214. doi: 10.1111/j.1529-8817.1981. tb00841.x

López Barreiro, D., Prins, W., Ronsse, F., and Brilman, W. (2013a). Hydrothermal liquefaction (HTL) of microalgae for biofuel production: state of the art review and future prospects. Biomass Bioenergy 53, 113-127. doi: 10.1016/j.biombioe. 2012.12.029

López Barreiro, D., Zamalloa, C., Boon, N., Vyverman, W., Ronsse, F., Brilman, W., et al. (2013b). Influence of strain-specific parameters on hydrothermal liquefaction of microalgae. Bioresour. Technol. 146, 463-471. doi: 10.1016/j. biortech.2013.07.123

Mata-Alvarez, J., Mace, S., and Llabres, P. (2000). Anaerobic digestion of organic solid wastes. an overview of research achievements and perspectives. Bioresour. Technol. 74, 3-16. doi: 10.1016/S0960-8524(00)00023-7 
Matasci, N., Hung, L.-H., Yan, Z., Carpenter, E. J., Wickett, N. J., Mirarab, S., et al. (2014). Data access for the 1,000 plants (1KP) project. GigaScience 3:17. doi: 10.1186/2047-217X-3- 17

McCarty, P. L. (1964). Anaerobic waste treatment fundamentals. Public Works 95, $107-112$.

Merchant, S. S., Prochnik, S. E., Vallon, O., Harris, E. H., Karpowicz, S. J., Witman, G. B., et al. (2007). The Chlamydomonas genome reveals the evolution of key animal and plant functions. Science 318, 245-250. doi: 10.1126/science.1143609

Minowa, T., Yokoyama, S., Kishimoto, M., and Okakura, T. (1995). Oil production from algal cells of Dunaliella Tertiolecta by direct thermochemical liquefaction. Fuel 74, 1735-1738. doi: 10.1016/0016-2361(95)80001-X

Moody, J. W., McGinty, C. M., and Quinn, J. C. (2014). Global evaluation of biofuel potential from microalgae. Proc. Natl. Acad. Sci. U.S.A. 111, 8691-8696. doi: 10.1073/pnas.1321652111

Munoz-Blanco, J., Hidalgo-Martinez, J., and Cárdenas, J. (1990). Extracellular deamination of 1-amino acids by Chlamydomonas reinhardtii Cells. Planta 182, 194-198. doi: 10.1007/BF00197110

Nagase, H., Yoshihara, K.-I., Eguchi, K., Okamoto, Y., Murasaki, S., Yamashita, R., et al. (2001). Uptake pathway and continuous removal of nitric oxide from flue gas using microalgae. Biochem. Eng. J. 7, 241-246. doi: 10.1016/S1369-703X(00) $00122-4$

Neumuller, K. G., Carvalho de Souza, A., Van Rijn, J., Appeldoorn, M. M., Streekstra, H., H. Schols, A., et al. (2013). Fast and robust method to determine phenoyl and acetyl esters of polysaccharides by quantitative 1H NMR. J. Agric. Food Chem. 61, 6282-6287. doi: 10.1021/jf401393c

Oren, A. (2005). A hundred years of Dunaliella research: 1905-2005. Saline Systems 1:2. doi: 10.1186/1746-1448-1-2

Packer, M. (2009). Algal capture of carbon dioxide; biomass generation as a tool for greenhouse gas mitigation with reference to New Zealand energy strategy and policy. Energy Pol. 37, 3428-3437. doi: 10.1016/j.enpol.2008.12.025

Palenik, B., and Morel, F. M. M. (1990). Amino acid utilization by marine phytoplankton: a novel mechanism. Limnol. Oceanogr. 35, 260-269. doi: 10. 4319/lo.1990.35.2.0260

Palenik, B., and Morel, F. M. M. (1991). Amine oxidases of marine phytoplankton. Appl. Environ. Microbiol. 57, 2440-2443.

Parkin, G. F., and Owen, W. F. (1986). Fundamentals of anaerobic digestion of wastewater sludges. J. Environ. Eng. 112, 867-920. doi: 10.1061/(ASCE)073393721986112:5(867)

Pattison, D. I., Rahmanto, A. S., and Davies, M. J. (2012). Photo-oxidation of proteins. Photochem. Photobiol. Sci. 11, 38-53. doi: 10.1039/C1PP05164D

Piedras, P., Pineda, M., Munoz, J., and Cardenas, J. (1992). Purification and characterization of an 1-amino-acid oxidase from Chlamydomonas reinhardtii. Planta 188, 13-18. doi: 10.1007/BF00198934

Prochnik, S. E., Umen, J., Nedelcu, A. M., Hallmann, A., Miller, S. M., Nishii, I., et al. (2010). Genomic analysis of organismal complexity in the multicellular green alga Volvox carteri. Science 329, 223-226. doi: 10.1126/science. 1188800

Rasala, B. A., and Mayfield, S. P. (2015). Photosynthetic biomanufacturing in green algae; production of recombinant proteins for industrial, nutritional, and medical uses. Photosynth. Res. 123, 227-239. doi: 10.1007/s11120-014-9994-7

Sauer, N. (1984). A general amino-acid permease is inducible in Chlorella vulgaris. Planta 161, 425-431. doi: 10.1007/BF00394573

Sheehan, J., Dunahay, T., Benemann, J., and Roessler, P. (1998). A Look Back at the US Department of Energy's Aquatic Species Program: Biodiesel from Algae, Vol. 328. Golden, CO: National Renewable Energy Laboratory. doi: 10.2172/ 15003040

Sialve, B., Bernet, N., and Bernard, O. (2009). Anaerobic digestion of microalgae as a necessary step to make microalgal biodiesel sustainable. Biotechnol. Adv. 27, 409-416. doi: 10.1016/j.biotechadv.2009.03.001
Srirangan, S., Sauer, M.-L., Howard, B., Dvora, M., Dums, J., Backman, P., et al. (2015). Interaction of temperature and photoperiod increases growth and oil content in the marine microalgae Dunaliella viridis. PLoS ONE 10:e0127562. doi: 10.1371/journal.pone. 0127562

Su, Y. H., Frommer, W. B., and Ludewig, U. (2004). Molecular and functional characterization of a family of amino acid transporters from Arabidopsis. Plant Physiol. 136, 3104-3113. doi: 10.1104/pp.104.045278

Tegeder, M. (2012). Transporters for amino acids in plant cells: some functions and many unknowns. Curr. Opin. Plant Biol. 15, 315-321. doi: 10.1016/j.pbi.2012. 02.001

Tegeder, M., and Ward, J. (2014). Molecular evolution of plant AAP and LHT amino acid transporters. Evol. Transporters Plants 3:84. doi: 10.3389/fpls.2012. 00021

Tomita, M., Irie, M., and Ukita, T. (1969). Sensitized photooxidation of histidine and its derivatives. products and mechanism of the reaction. Biochemistry 8 , 5149-5160. doi: 10.1021/bi00840a069

Tsukahara, K., Kimura, T., Minowa, T., Sawayama, S., Yagishita, T., Inoue, S., et al. (2001). Microalgal cultivation in a solution recovered from the low-temperature catalytic gasification of the microalga. J. Biosci. Bioeng. 91, 311-313. doi: 10.1016/S1389-1723(01)80140-7

US Department of Energy (2010). National Algal Biofuels Technology Roadmap. US Department of Energy, Office of Energy Efficiency and Renewable Energy, Biomass Program. College Park, MD: US Department of Energy.

Vallon, O., Bulté, L., Kuras, R., Olive, J., and Wollman, F.-A. (1993). Extensive accumulation of an extracellular L-amino-acid oxidase during gametogenesis of Chlamydomonas reinhardtii. Eur. J. Biochem. 215, 351-360. doi: 10.1111/j. 1432-1033.1993.tb18041.x

Vergara-Fernández, A., Vargas, G., Alarcón, N., and Velasco, A. (2008). Evaluation of marine algae as a source of biogas in a two-stage anaerobic reactor system. Biomass Bioenergy 32, 338-344. doi: 10.1016/j.biombioe.2007. 10.005

Wang, W.-C., Allen, E., Campos, A. A., Cade, R. K., Dean, L., Dvora, M., et al. (2013). ASI: Dunaliella marine microalgae to drop-in replacement liquid transportation fuel. Environ. Progr. Sustain. Energy 32, 916-925. doi: 10.1002/ ep.11855

Ward, A. J., Lewis, D. M., and Green, F. B. (2014). Anaerobic digestion of algae biomass: a review. Algal Res. 5, 204-214. doi: 10.1016/j.algal.2014.02.001

Wheeler, P. A., North, B. B., and Stephens, G. C. (1974), Amino acid uptake by marine phytoplankters. Limnol. Oceanogr. 19, 249-259. doi: 10.4319/lo.1974. 19.2.0249

Wijffels, R. H. and Barbosa, M. J. (2010). An outlook on microalgal biofuels. Science 329, 796-799. doi: 10.1126/science.1189003

Zhang, W., Zhang, Z., and Yan, S. (2015). Effects of various amino acids as organic nitrogen sources on the growth and biochemical composition of Chlorella pyrenoidosa. Bioresour. Technol. 197, 458-464. doi: 10.1016/j.biortech.2015. 08.100

Conflict of Interest Statement: The authors declare that the research was conducted in the absence of any commercial or financial relationships that could be construed as a potential conflict of interest.

Copyright (ㄷ 2017 Murphree, Dums, Jain, Zhao, Young, Khoshnoodi, Tikunov, Macdonald, Pilot and Sederoff. This is an open-access article distributed under the terms of the Creative Commons Attribution License (CC BY). The use, distribution or reproduction in other forums is permitted, provided the original author(s) or licensor are credited and that the original publication in this journal is cited, in accordance with accepted academic practice. No use, distribution or reproduction is permitted which does not comply with these terms. 